\title{
THE STRUCTURE AND GROWTH OF THE INCISOR TEETH OF THE ALBINO RAT
}

\author{
WILLIAM H. F. ADDISON AND J. L. APPLETON, JR.
}

From the Antomical Laboratory of the University of Pennsylvania and The Wistar Institute of Anatomy, Philadelphia

TWENTY-NINE FIGURES

CONTENTS

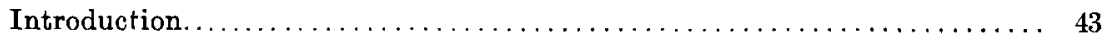

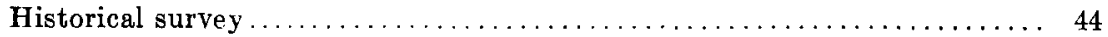

Material and methods $\ldots \ldots \ldots \ldots \ldots \ldots \ldots \ldots \ldots \ldots \ldots \ldots \ldots \ldots \ldots \ldots \ldots$

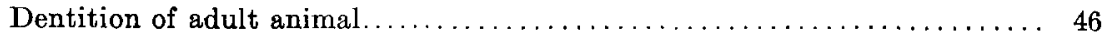

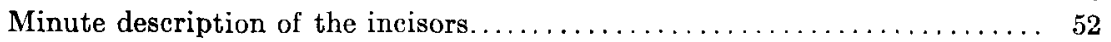

Microscopic structure of enamel and dentine $\ldots \ldots \ldots \ldots \ldots \ldots \ldots \ldots \ldots \ldots \ldots$

Development of the incisors $\ldots \ldots \ldots \ldots \ldots \ldots \ldots \ldots \ldots \ldots \ldots \ldots \ldots$

Detailed description of development up to time of eruption $\ldots \ldots \ldots \ldots \ldots, 61$

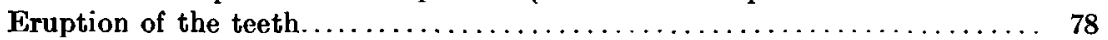

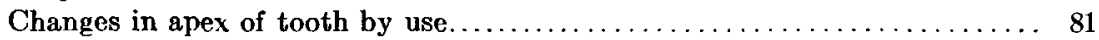

Description of mature tooth and tooth-forming organs, in 5-month animal. . 83

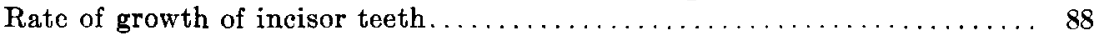

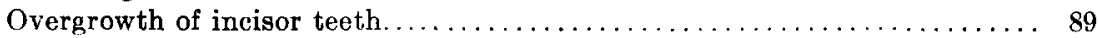

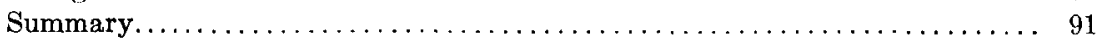

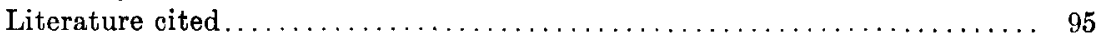

\section{INTRODUCTION}

The incisor teeth of the Rodentia have long been regarded by the zoologist as having a high value for the understanding of many of the characteristics of this order. For instance, in 1888, Cope wrote "nearly all the peculiarities of the rodent dental system and manner of mastication are the mechanical consequences of an increase in length of the incisor teeth." 'Tullberg ('98-'99) gives the taxonomic position of the genus Mus, proceeding from the more general to the more specific grouping: Rodentia, Simplicidentati, Sciurognathi, Myomorphi, Myoidei, Muriformes, Myodontes, Muridae, Murini, Mus. A consideration of these terms merely from an etymological view suggests the importance of the teeth and jaws in the classifi- 
cation of the gnawing animals. The observations here recorded are based on the study of the cellular processes involved in the formation, eruption and growth of the incisor teeth in a single rodent form-Mus norvegicus albinus. An additional interest was lent to the work by the fact of the increasing use of this animal for laboratory purposes, which makes it desirable to learn the time-relations of its life-processes, as a basis of comparison in various forms of experimental studies. Although the rodent incisors have been the object of much study, few observers have carried out their observations through the complete life-history, including developmental stages and adult structure, in one form of animal and this it has been our aim to do.

\section{HISTORICAL SURVEY}

Oudet ('23) proved the phenomenon of permanent growth in the incisor teeth of rodents by cutting off the teeth at the gingival margin and observing that they were regenerated. Retzius ('37) and others noted the overgrowth of these teeth in cases of malocclusion. MacGillavry ('76) observed the rate of growth of the incisors of a rabbit by making marks on the teeth and noting the gradual advance and disappearance of these marks, as the teeth grew out and were worn away.

Questions which have called forth much study and controversy* are (1) does the rodent incisor belong to the milk or to the permanent dentition; and (2) which of the three incisors of the typical mammalian dental formula does it represent. Without exception, all who have studied the first question agree that the large rodent incisor belongs to the second or permanent dentition. These same studies show that abortive milk incisors occur in a varying degree in the several families of the Rodentia; and that they are slightly, if at all, represented in the Muridae. As to the second question, Cope on palaeontological evidence decided that the large rodent incisor was $\mathrm{I}_{2}$. Adloff ('98) on embryological evidence confirmed this view. Freund ('92), Woodward ('94) and Stach ('10) believed it to be $I_{1}$. Weber ('04) has given a resumé and extended bibliography of this work, up to the date of his writing. 
The histology of the incisor' was briefly described by Owen ('40-'45) and more completely studied by J. Tomes ('50). The latter found a considerable diversity of arrangement of the enamel prisms in the different families of the order, so that in many cases he was able correctly to refer a tooth to a particular family by a simple inspection of thin sections of its enamel. Von Brunn ('87) showed that at eruption the tip of the incisor of the albino rat is free from enamel, and Sachse ('94) confirmed this on Mus musculus. J. L. Williams ('96), in a comparative study of the formation of enamel, gives a number of good illustrations of the structure of the enamel and enamel-organ of the rat, prepared from microphotographs.

Ryder ('78) and Cope ('88), in harmony with their views on the "Origin of the Fittest," described the form and position of the rodent incisor as manifestations of a most efficient mechanical system; and studied the various effects on skull topography, necessitated by adaptation to this system.

The enamel organ of the albino rat was studied by von Brunn ('87) who described in some detail the differences in structure between its functional labial portion and its non-functional lingual side. He also described the early continuity of the lingual side of the enamel-organ and its later penetration by the surrounding connective tissue. Roetter ('89), studying Mus musculus, denied von Brunn's position in regard to the invasion of the lingual side of the enamel-organ by connective tissue, and Sachse ('94), also using Mus musculus, agreed with Roetter and described the continuity of the lingual portion as persisting through life.

The development of the rodent incisor has been studied especially by Roetter ('89), Sachse ('96) and Meyerheim ('98). Burckhardt ('06), in his description of the development of the persistently growing rodent incisor in $\mathrm{O}$. Hertwig's Handbuch der Entwickelungslehre has followed chiefly Sachse's work upon Mus musculus. In both Weber ('04) and Hertwig ('06) are extensive bibliographies and in these may be found all references not fully given in our appended list of literature cited. 


\section{MATERIAI AND METHODS}

The albino rat is a variety of Mus norvegicus, the common gray rat (Donaldson '12). This has been shown by similarity of skull measurements (Hatai '07) and of hemoglobin crystals (Reichert and Brown '10) and also by the fact that the two interbreed freely.

The material used was obtained from the rat colony of The Wistar Institute. Serial sections in paraffin or in paraffincelloidin were made of decalcified heads of fetuses taken at daily intervals from the 16th day onwards until birth, and of jaws of animals newly-born and at short intervals until one month, and of several older stages. Serial sections of fetuses younger than 16 days were examined in the collection of The Wistar Institute. Ground sections were made of the isolated teeth, and the petrifaction method of imbedding in Canada balsam was used to prepare the teeth and adjacent soft parts in situ. Also a series of prepared crania, some entire and some disarticulated, was made at selected ages, varying from birth to old age. The 'gold dust' method of Davison, as tested out for different ages at The Wistar Institute was used for the preparation of the former, and maceration in tap water for the latter. Schultze's clearing method was found useful in studying the early periods of calcification.

\section{DENTITION OF ADULT ANIMAL}

The dental formula of the albino rat is $\mathrm{I} \frac{1}{1}, \mathrm{C} \underset{0}{0}, \mathrm{P} \underset{0}{0}, \mathrm{M} \frac{3}{3}$. There is only one set of teeth, and hence the dentition is monophyodont. The time of eruption of the various teeth extends over a period of $3 \frac{1}{2}$ weeks. The incisors are the first to appear, viz., at 8 to 10 days after birth. The first and second molars erupt at about the 19 th and 21 st days respectively, and it is after this period that the young animals may be weaned and are able to maintain an independent existence, as far as food is concerned. The third molars are delayed until 2 weeks later and do not appear until about the 35th day. 

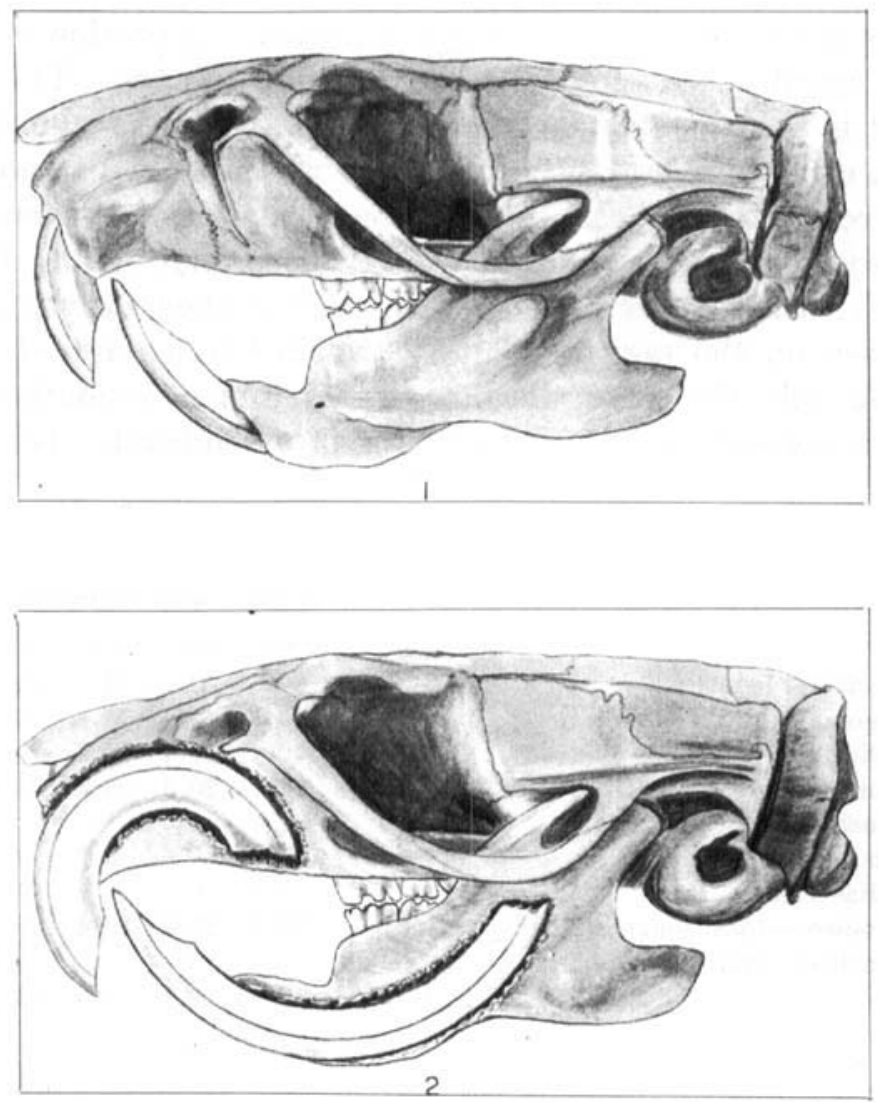

Fig. 1 Cranium of a 5-month albino rat. $\times 2$.

Fig. 2 Cranium of a 5-month albino rat, with the bony alveoli dissected away to show the entire length of the incisor teeth. $\times 2$.

The incisors are permanently-growing (or rootless) teeth, while the molars have a definite limited period of development and acquire roots. A wide diastema separates the incisors from the molars as may be seen by reference to figure 1 . The incisors are strongly curved and Owen ('40-'45) has described the lower incisor as being the smaller segment of a larger circle, and the upper incisor as the larger segment of a smaller circle. In the lower incisor of the albino rat this statement needs a slight modification. For while the curvature of the upper in- 
cisor is in one plane only, the lower incisor is a portion of a flattened spiral, possessing a curve in three planes. The upper incisor is a segment of a true circle (at 5 months about $210^{\circ}$ ) and in cases of overgrowth it has often been known to complete the circle. In the case of the lower incisor, however, when we project it on the sagittal, frontal or coronal planes, it gives in each case a curve. It was the very evident curved projection seen on the sagittal plane to which Owen referred. Considering only this view, the lower incisor of a 5-month animal forms a segment of about four-fifths of a semicircle (140-145 $)$.

TABLE 1

\begin{tabular}{|c|c|c|c|c|c|c|c|}
\hline & $\begin{array}{c}23 \\
\text { DAYS }\end{array}$ & $\begin{array}{c}41 \\
\text { DAYS }\end{array}$ & $\begin{array}{c}10 \\
\text { WEEKS }\end{array}$ & $\mid \begin{array}{c}15 \\
\text { WEEKS }\end{array}$ & $\left|\begin{array}{c}5 \\
\text { MoNiths }\end{array}\right|$ & \begin{tabular}{c|}
8 \\
MONTHS
\end{tabular} & $\begin{array}{c}10 \\
\text { MONIHS }\end{array}$ \\
\hline & $m m$ & $m m$. & $m m$. & $m m$. & $\mathrm{mm}$. & $m m$. & $m m$ \\
\hline Naso-occipital length. . & 29.7 & 32.5 & 39 & 40 & 43 & 44 & 46.5 \\
\hline Interzygomatic.......... & 13.7 & 14 & 14.5 & 14.6 & 15.4 & 15.1 & 15.5 \\
\hline Uppor diastema............ & 7.4 & 9.5 & 10 & 11.4 & 12.3 & 12.5 & 13 \\
\hline Upper incisor-total length... & 12.8 & 15 & 18.3 & 20.3 & 23.3 & 23.7 & 26.2 \\
\hline Upper incisor-extra-alveolar & & & & & & & \\
\hline length. . . . . . $\ldots \ldots \ldots \ldots$ & 5.1 & 5.5 & 7 & 8.4 & 8.7 & 9 & 93 \\
\hline Lower diastema.......... & 4.6 & 5 & 5.6 & 6 & 6.7 & 7 & 6.8 \\
\hline Lower incisor-total length... & 18.1 & 21.7 & 25.5 & 26.4 & 29.4 & 29.9 & 31.3 \\
\hline Lower incisor-extra-alveolar & & & & & & & \\
\hline length. .............. & 6.5 & 7 & 10.5 & 11.4 & 11.6 & 12 & 12.4 \\
\hline
\end{tabular}

Measurements of the incisors and skulls of animals of different ages, were made as shown in table 1.

The teeth were measured along their convex surfaces by means of silk thread wet with water, and applied to the object to be measured. The thread was then cut with scissors at the end of the object, straightened on paper and measured to tenths of millimeters.

A consideration of table 1 , shows in a definite way the peculiarities characteristic of the dentition, not only of the rat but of rodents in general. As is well known, these are the great development of the incisors, the wide diastema, and the consequent posterior position of the molar teeth as related to the rest of the skull. Cope ('88) wrote that he considered "the 
increase in the length of these teeth has been due to their continued use, as believed by Ryder." The effects of this increased elongation upon surrounding parts he described under several different headings, but reference will be made here only to one, viz., upon the shape of the glenoid cavity. "A peculiarity of the masticating apparatus is the lack of a postglenoid process, and the consequent freedom of the lower jaw to slide backward and forward in mastication. Appropriately to this motion, the condyle of the mandible is extended antero-posteriorly and the glenoid cavity is a longitudinal instead of a transverse groove."

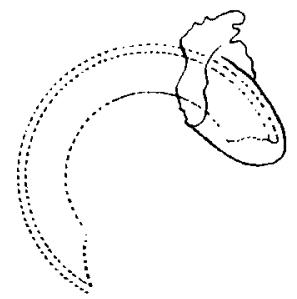

Fig. 3 Thimble-shaped portion of the maxilla bone, in which the basal end of the upper incisor is located. $\times 2$.

The lower incisors are longer and more slender than the upper and extend far back in the mandible, beneath the lower molars, to near the sigmoid notch. The upper incisors are contained within the premaxilla and maxilla, the basal end occupying a thin-walled, thimble-shaped recess of bone (fig. 3 ) to be seen best in the disarticulated skull, and which is attached at only one limited region to the rest of the maxilla. In both upper and lower teeth, the intra-alveolar portions are longer than the extra-alveolar. When one compares the extra-alveolar lengths of the upper and lower teeth of the mature animal, the latter are always greater, and, as may be seen by reference to table 1, the difference in lengths becomes greater with increased age and size.

In both upper and lower incisors the bone is so contoured around their imbedded portions that their course may be easily recognized. The basal end or foraminal apex of the lower 
incisor forms on the outer aspect of the mandible a marked rounded projection, directed upwards and backwards beneath the coronoid process, and sometimes extending slightly posteriorly beneath the sigmoid notch. Almost directly opposite this projection on the mesial aspect of the mandible is the inferior dental foramen. This projection marks the position of the growing end of the formative organs of the incisor in the adult. In the new-born animal it is not present, nor at the end of the first month. By the age of $2 \frac{1}{2}$ months it may be recognized, and thereafter it increases in prominence and constitutes a very evident feature of the bone. This region of the growing end of the tooth is protected by the zygomatic arch, and also by the overlying muscles.

The course of the upper incisor may also be readily followed in the prepared skull. Laterally it is covered with a thin rounded layer of bone. Mesially it forms an elevated, distinct ridge projecting markedly into the nasal fossa. In the adult the position of its basal or growing end is not so prominent as that of the lower incisor. As these incisor teeth are an indispensable part of the rodents' existence their importance demands protection from traumatism which might injure their growing pulp. Here in the upper incisors, this protection is afforded by a flange of the maxilla running parallel to the lateral wall of the cranium, as shown in figure 1 , as well as being encased in a separate thimble-shaped recess of bone (fig. 3), beneath, and separated by a narrow interval from, the outer layer of the maxilla. These details are in harmony with Cope's idea ('88) of the influence of the incisors in moulding the general topography of the rodent skull.

The diastema in the upper jaw is always longer than in the lower (fig. 1). By reference to table 1 it may be seen that in the mature animal the upper is nearly twice as long as the lower, but that in the younger stages the difference is not so great. The upper hair-covered lips are infolded into the diastema, dividing the oral cavity into an anterior and posterior compartment. This arrangement probably prevents the débris and splinters of gnawing from entering the main oral cavity. 
The mandibular symphysis is formed of fibrous tissue and allows independent rotation of either ramus with its contained tooth. This lateral movement of the lower incisors appears to be under the control of the will of the animal. According to the observations of Jolyet and Chaker ('75) this mobility has a definite purpose in mastication. They observed a rapid alter-
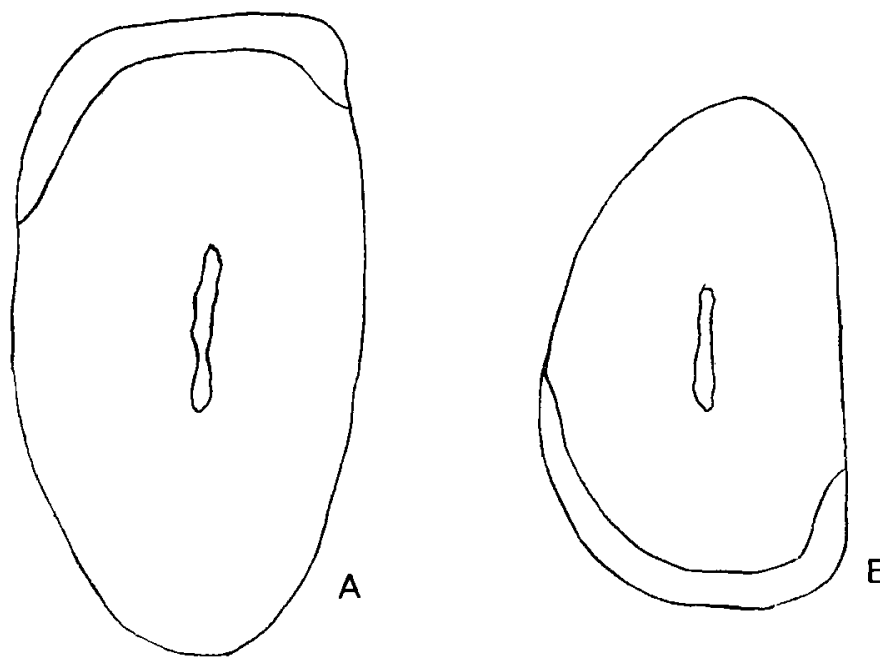

Fig. 4 Cross-sections of the (a) upper and (b) lower incisor teeth of a 5-month albino rat, taken near the alveolar margins. These show the arrangement of the enamel and the dentine, and the difference in contour of the enamel in the upper and lower teeth. The mesial surface of each tooth is towards the right side. $\times 15$.

nate separation and approximation of the tips of the lower incisors in the act of attempting to bite into a match or other slender object offered to the animal. At the same time the upper incisors were held stationary.

Mention may be made here of a point of variation among the Rodentia in the relation of the angle of the lower jaw to the sheath of bone around the lower incisor. In the Myomorphi and Sciuromorphi the angle arises from the lower surface of the incisive sheath, while in Hystrix the angle arises entirely on the outer side. 
Ryder (77) suggested a classification of rodents based on the shape of their incisors as seen in cross-section. In some genera the diameter of the teeth is less from side to side, than in the antero-posterior direction, while in others the reverse condition is found. The present form belongs to the former group, as is shown in figure 4. From the consideration of many rodents, Ryder deduced the general principle, that where the incisors are thicker in the antero-posterior direction, the gnawing habit is greatly developed.

\section{MINUTE DESCRIPTION OF THE INCISORS}

Enamel and dentine make up the hard tooth substance, enclosing the pulp. Owen, in his "Odontography" ('40-'45, p. 399) said that there existed a general investment of cementum over the whole tooth structure. J. Tomes ('50, p. 533) was not able to agree entirely but said that in most, if not in all, incisors of rodents cementum could be seen investing the posterior surface. In the rat, it is not apparent that there is any cementum at all. The enamel is usually colored with a pigment which is yellowish in the young but becomes orange-colored with age, and is usually more pronounced in the upper than in the lower incisors. At 13 days, there is as yet no color, but at 21 days a slight tinge of yellow is perceptible in the uppers, but none in the lowers. At 25 days the uppers are distinctly yellow, and the lowers have now acquired a slight color. At 38 days, these colors have intensified, the uppers having more pigment than the lowers; and in the mature animal the same relation continues, the uppers being orange-colored and the lowers yellow. The enamel is found principally on the labial side, and this accounts for the shape of the occlusal surface. For, the enamel being harder than the dentine, the latter is more easily worn away by the action of the opposing tooth, and the more resistant enamel remains as the cutting edge or point. The shape of the incisal end of the upper and lower teeth is different, being chisellike (scalpriform) in the upper, and more rounded and narrower in the lower. The incisal line is also usually different in the 
upper and lower teeth. In the former, it is often slightly concave from side to side, while in the latter it is convex (fig. 5).

As is shown in figures 1 and 5 the occlusal surface is an elongated concave area on the lingual aspect of the teeth, and in the living animal extends practically to the gingival margin. Due to the difference in the curve of the upper and lower teeth, the occlusal surface of the lower teeth is always longer than that of the upper, and in the mature animal it is usually found to be nearly twice as long.

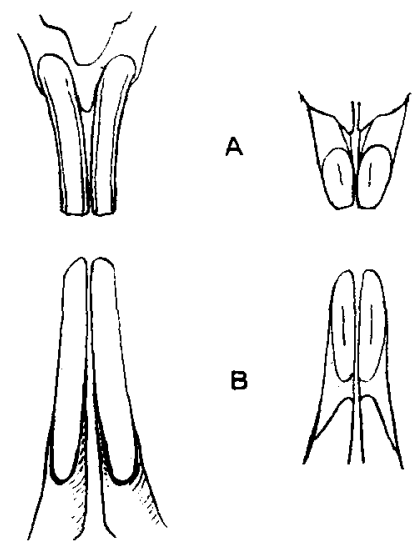

Fig. 5 Labial and lingual aspects of the extra-alveolar portions of the (a) upper and (b) lower incisors of a 5-month albino rat, showing the occlusal surfaces and incisal edges of the teeth, and the outline of the bony alveolar margins. $\times 2$.

It follows that because these teeth are constantly growing, the occlusal surfaces are constantly being worn away. As we shall see, when discussing the growth of the teeth, the elongated temporo-mandibular articulation is important, in allowing the teeth to have either the position pictured in figure 1 or to have the opposite relation, with the lower teeth outside of the upper. Thus the very important factor in the animal's economy-the proper regulation of the length of the opposing incisors - is controlled by their own inter-action. 
The pulp-chamber has the characteristic shape found in all permanently growing teeth, as is well seen, for instance, in the elephant's incisor. Its cross-area is greatest at the basal end of the tooth, and gradually diminishes anteriorly. The pulpchamber is found to extend in the tooth beyond the line of the gingivus, and very nearly to the occlusal surface. The shape

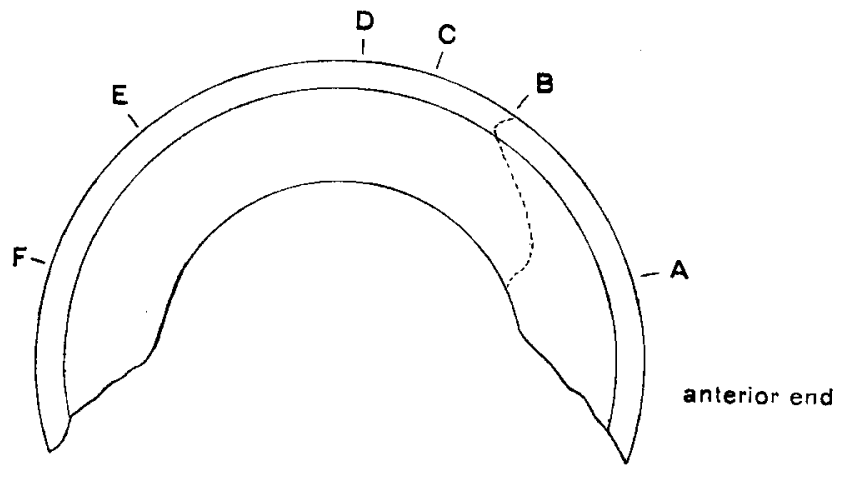

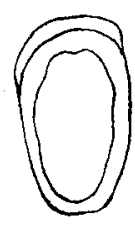

$\boldsymbol{F}$

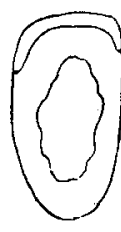

E

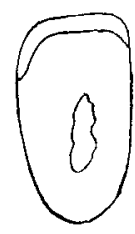

D

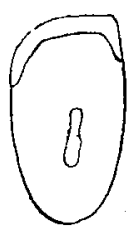

C

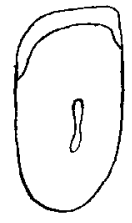

B

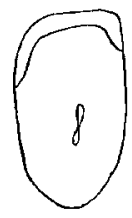

A

Fig. 6 Upper incisor of a 5-month albino rat $(\times 5)$ and cross-sections of it at different points $(\times 8)$, to show the relative cross-area of the dentine and of the pulp chamber at these regions. The dotted line indicates the position of the margin of the alveolus.

in cross-section of the pulp-chamber at different levels may be seen by reference to figure 6 . The position of the filled-in pulpchamber is usually well marked on the occlusal surfaces as a line (fig. 5). In weathered specimens of rats' teeth from recent geological formations this last-formed part which fills in the pulpchamber at the end of the tooth, is usually found to be lacking, and is evidently not of the same hardness as the surrounding parts of the tooth. 


\section{MICROSCOPIC STRUCTURE OF ENAMEL AND DENTINE}

Sections of enamel show two layers; an outer thin and an inner thicker layer, as noted by Owen ('40-'45, p. 399). The enamel rods run in different directions in the two layers as fully described by $\mathrm{J}$. Tomes in 1850 . In the inner layer the enamel rods appear to run in two sets, obliquely to one another, while in the outer layer the rods are all parallel. The outer layer has also been called the fibrous layer, and in its superficial part is situated the yellow or orange pigment which gives the color to the enamel.

Figures 7 and 8 show the arrangement of the enamel rods in the two layers. In the inner or plexiform layer, when examined in cross section, the alternating series of enamel rods decussate, forming an angle varying between 70 and $90^{\circ}$. In longitudinal sections (fig. 26) these rods are slightly S-shaped, running outwards from the enamel-dentine surface at an angle of $\mathbf{5 0}$ to $54^{\circ}$, and inclining towards the anterior end of the tooth. Figure 8 is from a ground-section in which the enamel was broken during the process of preparation, and the broken edge shows distinctly the two sets of rods running at nearly right angles to each other. Under high magnification the rods are slightly notched.

In cross-sections of the outer fibrous layer, the rods are parallel and form in the mid-line of the tooth an angle of $90^{\circ}$ with the outer surface. As one proceeds away from the mid-line of the tooth, whether mesially or laterally, the general tendency of the long axis of the rods as they pass from the dentine junction to the periphery, is to incline in the direction away from the mid-line of the tooth. The ameloblasts usually form an obtuse angle with the rods of the outer layer and seldom coincide in direction with them (fig. 7). In longitudinal sections the rods of the outer layer are not usually so distinctly seen as in cross-sections. In favorable longitudinal sections, however, they are seen to run quite obliquely, inclining towards the apex of the tooth, and forming an angle of 20 to $25^{\circ}$ with the plane of the enamel-dentine junction. The pigment, as will be seen 

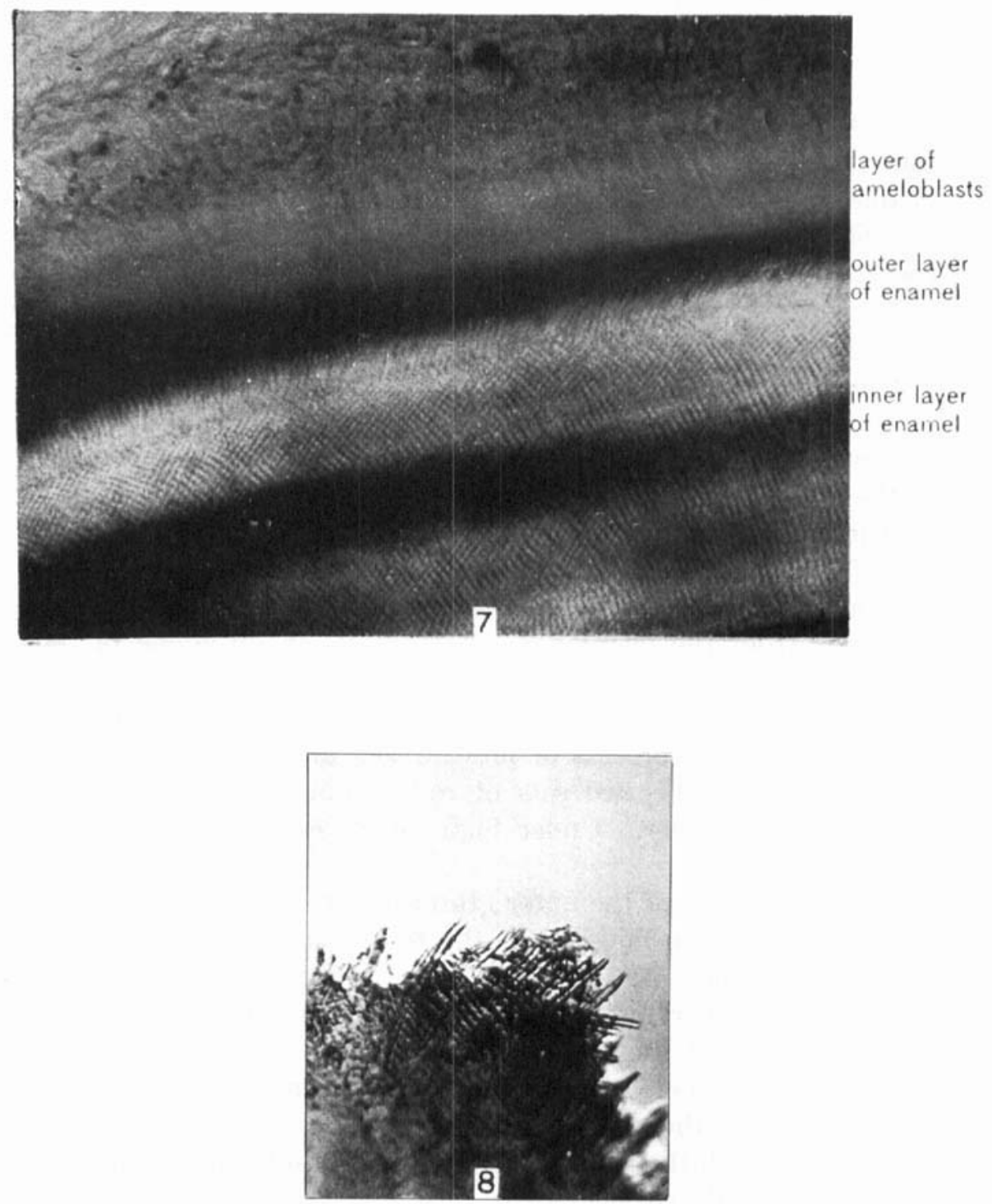

lig. 7 Portion of cross-section of lower incisor with enamel-organ, prepared by the petrifaction method, showing the decussation of the enamel-rods in the inner or plexiform layer and their parallel arrangement in the outer or fibrous layer. $\times 350$.

Fig. 8 Small piece of enamel, showing the rods of the inner or plexiform lityer running in two directions nearly at right angles to one another. $\times 350$. 
below, is confined to the outermost part of the fibrous layer. There appears to be no Nasmyth's membrane over the enamel, which means that there has been a complete transformation of the enamel matrix into enamel rods. The pigment extends about two-thirds of the total length of the upper tooth, and about one-half of the total length of the lower tooth, and hence it follows that the deposition of enamel is completed within the basal third of the upper and the basal half of the lower tooth. By examining cross-sections of the tooth at different regions (fig. 6) it would seem that the full thickness of the enamel is attained within even a smaller area at the basal end of the tooth.

The arrangement of the enamel over the labial aspect of the upper and lower teeth is shown in figure 4, drawn from crosssections of the teeth of a 5-month animal. In both teeth the sections were made just posterior to the alveolar border. In both upper and lower teeth the enamel is thickest over the labial aspect, and is continued over the adjacent mesial and lateral surfaces. In both, the enamel is continued farther on the lateral than on the mesial surfaces, and relatively farther on the lateral surface in the lower than in the upper tooth. In the upper tooth the enamel has a flattened external surface labially, while in the lower it has a rounded contour. In the upper there is a distinct labio-mesial and a labio-lateral angle, the enamel being somewhat thicker at the former. In the lower there is a labio-mesial angle, though less prominent than in the upper, and the labio-lateral angle is practically absent.

In a 5-month animal the thickness of the enamel and its constituent layers was measured in the mid-line of the teeth, as follows:

\begin{tabular}{|c|c|c|}
\hline & $\begin{array}{c}\text { Upper } \\
\mu\end{array}$ & $\begin{array}{c}\text { Lower } \\
\mu\end{array}$ \\
\hline Total thickness.......... & $.100-110$ & $140-150$ \\
\hline Outer fibrous layer $\ldots \ldots \ldots \ldots \ldots \ldots \ldots$ & $30-40$ & $20-30$ \\
\hline Pigmented portion of outer fibrous layer. & $.8-10-12$ & $6-8$ \\
\hline Inner plexiform layer.... & 70 & $120-125$ \\
\hline
\end{tabular}

It will be observed, however, in figure 4 that the enamel is not thickest in the mid-line of the upper tooth, but at the lateral and mesial angles. While the enamel of the upper tooth meas- 
ures only 100 to $110 \mu$ in the mid-line, it measures 160 to $180 \mu$ at the region of these angles, and is, therefore, thicker here than the enamel of the lower tooth. The increased thickness at the angles is principally in the inner plexiform layer, the other layer being increased only slightly or not at all. The outer fibrous layer is distinctly thicker in the uppers and has a slightly wider band of pigment in it superficially. This, no doubt, is the basis of the more deeply pigmented appearance of the labial surface of the upper as compared with the lower teeth.

The dentine, unlike the enamel, grows continually thicker as one passes towards the outer end of the tooth. At the basal, growing, end it begins as an extremely thin layer. The thickness at different points is seen in figure 6 . As the dentine increases in thickness, the pulp-chamber is in consequence proportionately reduced. At the distal end there is no longer any pulp-chamber and the site of its previous position has been filled in by the formation of a kind of secondary dentine. C. Tomes ('14) notes that "in some rodents the final closure of the axial tract takes place almost by a continuance of the formation of normal fine-tubed dentine, with very little secondary dentine of different structure, while in others there is a large area of dentine with vascular tracts in it." In the rat there is relatively little of this secondary dentine. It is laid down in irregular trabeculae, with the pulp tissue, including bloodvessels, at first within it. At the exposed surface, however, it forms a continuous granular mass with apparently no soft tissues in it (fig. 27). The ordinary dentine of the tooth is quite typical in structure, with numerous parallel dentinal tubules, each having many fine lateral branches. The tubules are slightly sinuous, and the lateral branches anastomose with those of neighboring tubules. Sometimes a tubule sends off at an acute angle a branch nearly equal in diameter to the continuation of the main tubule. This is usually in the dentine not covered by enamel. Where these large branches come off the diameter of the tubule is greater than elsewhere, measuring nearly $2 \mu$. Elsewhere the diameter varies from 1 to $1.7 \mu$. Slight differences may be seen between the tubules (a) in the dentine covered by enamel, and (b) in the dentine free from 
enamel. The tubules of the anterior region (a) of the dentine, covered by enamel, are more regularly parallel and have finer lateral branches than elsewhere. They also seem to taper slightly as one follows them towards the enamel. In the dentine not covered by enamel (b) the tubules are more sinuous and irregular, the irregularities marking the position of origin of the larger lateral branches. In all parts at the periphery of the dentine the tubules end in a great number of very fine anastomosing arching branches. As a consequence of the smaller diameter of the little tubules here, a narrow zone at the periphery of the dentine has usually a more homogeneous appearance than has the remainder. Towards the anterior end of the tooth, in the vicinity of the pulp-chamber, are vascular channels in the form of loops within the dentine. The tubules must necessarily take a curved course around these vascular channels, and thus the position of the vessels is more easily seen.

In the dentinal tubules Mummery ('12), Fritsch ('14) and others have demonstrated not only the processes of the odontoblasts, but also fine non-medullated nerve fibers. As to why the exposed dentine on the lingual aspect of the teeth is insensitive, there are no definite observations to decide. A contributing factor may be the compression which the pulp tissues undergo at the anterior end of the pulp-chamber, leading to the physiological cutting off of the nerve supply to the dentinal tubules.

\section{DEVELOPMENT OF THE INCISORS}

The times of the early stages of development of the incisors were seen as follows:

\footnotetext{
14-day fetus-slight thickening of oral epithelium

15-day fetus-distinct thickening and growth inwards of oral epithelium

16-day fetus-dental ledge and beginning of flask-shaped enamel organ

17-day fetus-dental papilla with crescentic enamel organ capping it

19-day fetus-both ameloblasts and odontoblasts differentiated

new-born animal-enamel and dentine formation begun

8 to 10 days-eruption of the tooth
}

Throughout life growth continues, and in the adult animal is on the average $2.2 \mathrm{~mm}$. per week in the upper and $2.8 \mathrm{~mm}$. per week in the lower incisor. 
The structures to be described here, as in the development of the crowns of all teeth, are the enamel-organ with the ameloblasts, and the dental papilla (which becomes the pulp-substance) with the odontoblasts. There are two factors, however, which alter the usual history of the development of these structures, and especially of the enamel-organ. First, in permanently growing teeth of which these are examples, all these structures continue functional throughout life, so that the enamelorgan is also a persistent structure. The other factor and one correlated to ssme extent with the first, is that the enamel is formed on one side of the tooth only, and here only does the enamel-organ develop to its most highly differentiated functional condition.

The history of the development and growth of the tooth may be conveniently considered in two stages (1) pre-eruptive, and (2) post-eruptive. The pre-eruptive stage extends from the 14th or 15th day of fetal life until eruption of the tooth takes place between the 8th and 10th post-natal days. Until near the time of birth there is no formation of enamel and dentine, but from birth onwards these substances are laid down rapidly, so that at eruption, the teeth have their characteristic elongated narrow form. This pre-eruptive stage is characterized by the rapid elongation of the tooth-forming organs, and by the teeth attaining very similar relations to the other structures of the jaw which the imbedded portions of the erupted teeth possess. Thus, the anlage of the lower incisor appears under the oral epithelium in the anterior region of the mandible, and grows continually backwards, until its growing end reaches the region beneath the developing molars. At this time the growing end presumably reaches a region which, by reason of its increasing calcification, offers resistance to further progress. The result of the ever-continuing mitotic division and cell growth at the basal end, is the pushing of the whole tooth and its formative organs, in the opposite direction, and the consequent eruption of the tooth. During the latter half of this pre-eruptive stage, the anterior tip of the developing tooth structure is immediately beneath the oral epithelium, and remains at a fixed 
point, while the posterior end is continually growing backwards and changing its relations. At eruption this condition changes, and the posterior extremity becomes practically a fixed point from which the whole tooth moves forward. That there is, however, a gradual change in the position of the posterior end of the tooth may be seen in figure 9. As the jaw grows, the entire tooth not only grows to keep the same general relative position, to surrounding structures, but it may be seen that the growing end progresses gradually posteriorly. In the full-grown animal this end occupies a distinct outpushing of the bone (fig. 1).

During the post-eruptive period, which continues throughout life, this outward growth is continued at a regular rate, and at the same rate the outer end has to be worn away. This wearing-away process would soon result in the pulp becoming exposed were not the occlusal end of the pulp-chamber also being continually filled in. As may be seen from figure 6 the dentine continues to increase in thickness until near the end of the tooth. This means that the odontoblasts continue their regular functional activity until near the end of the tooth. However, the final filling-in of the pulp-chamber to form a continuous hard occlusal surface is accomplished by the deposition of a hard matrix between the pulp elements and by the probable calcification of the latter. The result is, that as the tooth is worn away, the soft pulp never becomes exposed. Although the pulp reaches very near to the end of the tooth, a hard substance always fills in the end of the pulp-chamber, and so protects the pulp beneath.

\section{DETAILED DESCRIPTION OF DEVELOPMENT UP TO THE TIME OF ERUPTION}

The anlage of the enamel-organ of each incisor arises as an epithelial ingrowth, distinct and separate from that for the molars.

In frontal sections of the 14-day fetus, there are slight diffuse thickenings of the oral epithelium in the four positions, which represent the sites of the future tooth-formations. 

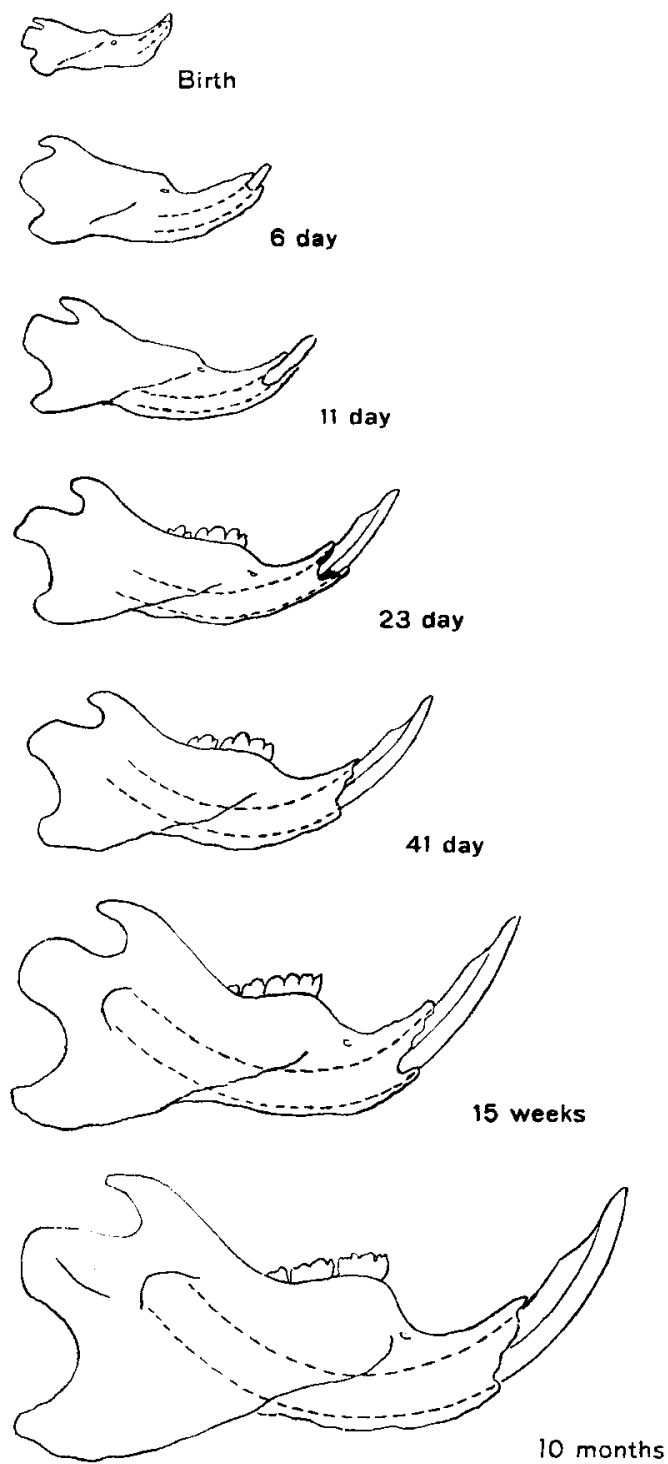

Fig. () Sieries of mandibles of the albino rat at ages varying from birth to wen months, viewed from the lateral aspect. These show the rhanging relation of the basal end of the incisor to the rest of the mundible during this period. 
At 15 days these thickenings have become more definite, and in the lower jaws especially have begun to push into the underlying mesenchyme, and may be described as the dental ledges or dental laminae.

At 16 days the ingrowths have continued to increase as broad masses of cells, pushing deeper into the underlying mesenchyme; and in the lower jaws the enamel organs may be distinguished as expanded structures, each connected by a slightly narrower mass of cells with the oral epithelium. In the upper jaws the differentiation of the enamel-organs from the remainder of the epithelial ingrowth is not so marked.

At 17 days (fig. 10) the dental papillae are beginning, and the enamel-organs in both upper and lower jaws have a crescentic outline. In the enamel-organs there is already an indication of the differentiation into three layers. As seen in sagittal sections, the papillae develop on the posterior side of the enamelorgans, thus foreshadowing the axis of growth of the toothforming organs in the antero-posterior direction.

\section{Eighteen-day fetus}

Series of frontal sections of 18-day lower jaws, show that the enamel-organs are growing over the dental papillae more rapidly on the labial and lingual surfaces than elsewhere, and extend more posteriorly on these surfaces. There are thus two projections of the posterior margin of each enamel-organ as already noted by Meyerheim ('98). The labial process is broad and thin and extends more posteriorly than the lingual process, which is somewhat narrower and thicker. One may here remark, therefore, an early difference between the labial and lingual part of the enamel-organ. Other differences which will soon appear have not yet developed. Thus, the inner layer of the enamel-organ is made up of columnar elements which are still similar in all parts, both labially and lingually. In the dental papilla no columnar odontoblasts are yet seen.

The enamel-organ remains connected with the surface epithelium by a broad band of epithelial cells. In the lower jaw, 
immediately laterad to the line of junction of this stalk of the enamel-organ to the surface epithelium, the lip furrow is a depression, the plane of which is continued into the underlying mesenchyme by an ingrowth of surface epithelium several layers of cells in thickness. It is by the subsequent splitting of this epithelial layer into two, that the separation of the lip will be effected.

\section{Nineteen-day fetus}

At 19 days, the enamel-organ in the upper jaw (fig. 11) is crescentic in outline in sagittal section, and in the lower jaw (fig. 12) is more elongated and conical in shape. At this age odontoblasts are first seen as columnar cells on the labial aspect of the mesodermal papilla. Three layers are recognizable in the enamel-organ, but the middle layer (enamel pulp), as has been also described by Sachse ('94) for the mouse, is extremely thin, and therefore is not present in the great quantity typically seen in the development of rooted teeth. It appears as a more lightly stained zone between the inner and outer layers, and is thickest at the basal end of the enamel-organ as shown in figures 11 and 12. It averages about $20 \mu$ in thickness and is made up of stellate cells loosely arranged. Already there is an indication of a compact arrangement of the two or three rows of cells next the inner layer of the enamel-organ, which will result in the so-called stratum intermedium seen at later ages. This middle layer is also slightly more abundant at the anterior end in the region where the enamel-organ is continuous with the stalk which joins it to the oral epithelium.

At this age the enamel-organs in the lower jaws have a greater total length than those in the upper, and especially in the lower

Fig. 10 Longitudinal section of upper jaw of 17-day fetus, showing tooth anlage of incisor, with the enamel-organ longer labially than lingually when measured from the point of junction of the stalk of the enamel-organ. The dental papilla is on the posterior aspect of the enamel-organ. $\times 70$.

Fig. 11 Longitudinal section of upper incisor anlage of 19-day fetus of albino rat, showing the crescentic outline of the enamel-organ, its greater length labially than lingually, and its thickened basal margin. $\times 70$.

Fig. 12 Longitudinal section of lower incisor anlage of 19-day fetus of albino rat, showing the conical outline of the enamel-organ and its greater length than in the upper jaw at the same age. $\times 70$. 

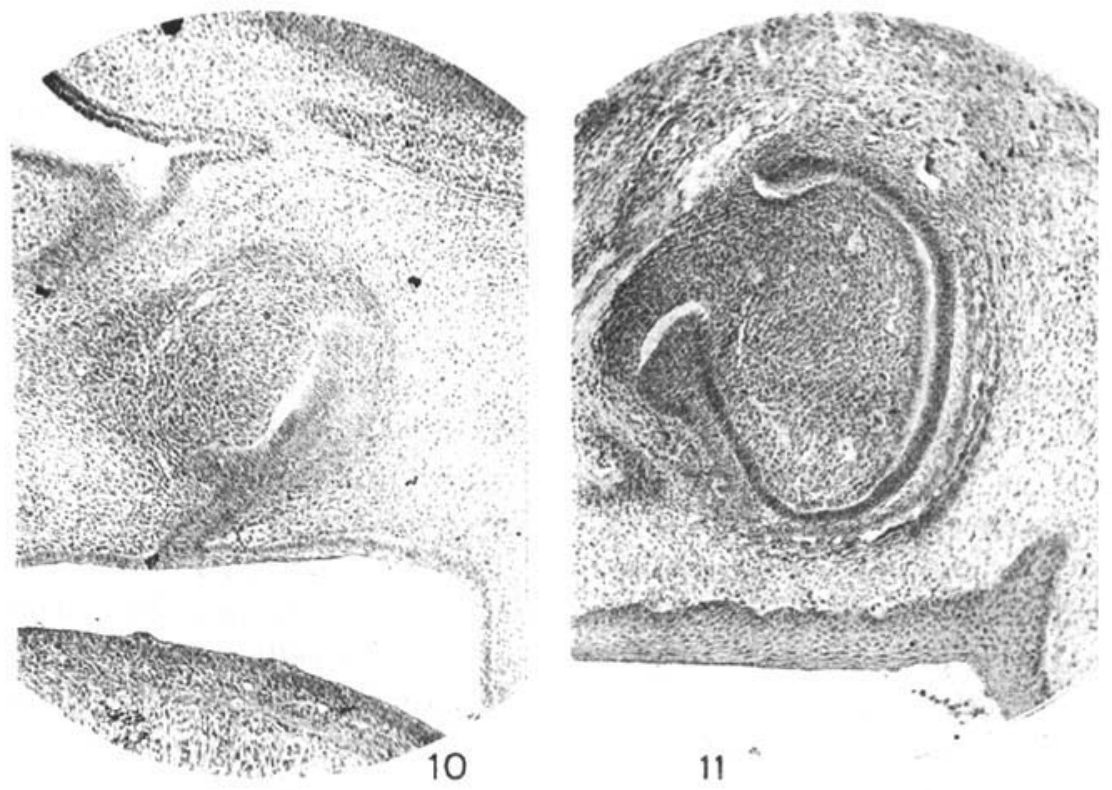

11

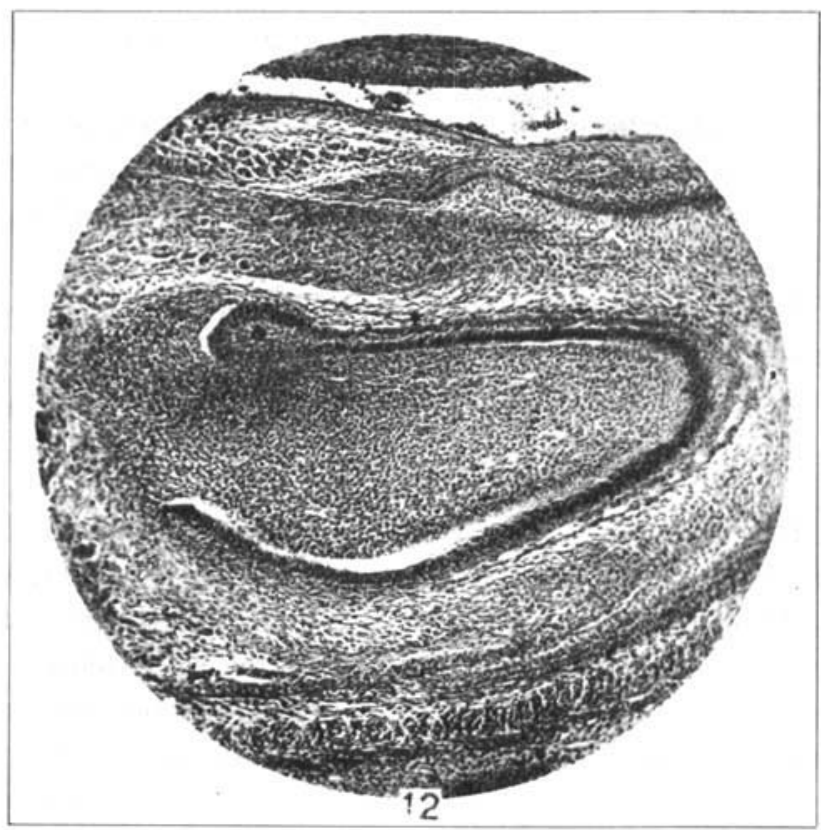


jaws distinct differences may be made out between the oral and labial sides of the tooth-forming organs. These differences are:

(1) The enamel-organ is longer labially than on the oral side.

(2) The staining of the inner layer of the enamel-organ on the labial side is more intense, and here the cells are slightly longer than in other parts of the enamel-organ, measuring $24 \mu$ in length and assuming the typical appearance of ameloblasts. Measurements show the similar cells on the lingual side to be about $20 \mu$ in length. It is also to be noted at this age that the site of the most advanced cells which are differentiating to become ameloblasts is not at the apex of the enamel-organ, as is the case in the development of rooted teeth. For as one follows the cells of the labial side of the enamel-organ from the apex towards the base, while at the apex the cells are columnar they become longer as one goes posteriorly, and then towards the base of the enamel-organ diminish again. So that the site of most advanced differentiation here is a short distance posterior to the apex on the labial side. This is true also of the developing odontoblasts which are longest opposite the tallest ameloblasts.

(3) The outer layer of the enamel-organ on the labial side is becoming slightly wavy in outline, and this denotes the beginning of the papillae, which form such a characteristic part of the mature functional enamel-organ (fig. 26).

(4) The odontoblasts are seen only on the labial side of the dental papilla.

Mitoses are abundant in all parts of the developing tissues.

\section{Twenty-one-day fetus}

Thus the anlage of the rodent incisor begins in the usual way, and for a short time continues along the typical mammalian course. From 19 days onward, however, the differences which have already begun, become more distinct and definite. At 21 days (end of gestation) the enamel-organ has become more definitely differentiated into a labial and a lingual region. Of the three constituent layers, the inner especially is strikingly different 
in these two parts. On the labial side at the anterior end, the organ has advanced to the condition where functional activity is beginning, while the oral side has remained stationary, or has actually retrogressed. Thus in the innermost layer on the labial side of the lower incisor, where the ameloblasts have begun to form enamel, these cells measure 30 to $34 \mu$ in length, while the non-functional cells on the oral side of the innermost layer are low columnar or cubical in shape and measure only $12 \mu$ in length (fig. 13). Comparison of these measurements with those at 19 days shows that the cells of the inner layer of the labial side of the enamel-organ have advanced in length from $24 \mu$ to 30 : or $34 \mu$, while the cells on the lingual side have decreased from 20 to $12 \mu$. There is, therefore, a primary tendency for the cells of the inner layer to develop equally in all parts, but very soon the nonenamel-forming cells of the lingual side begin to retrogress, while the functional cells of the labial side continue to grow. This constitutes another point of contrast with the development of the crowns of rooted teeth. For here in the 21-day fetus, when the enamel and dentine formation has just begun, these substances are thickest, not over the apex of the tooth-forming organs, as in the usual method, but at a short distance posterior to this point, on the labial surface. Thus, not only are the odontoblasts and the ameloblasts first differentiated on the labial side, posterior to the apex, but at this region enamel and dentine formation is also evidently first begun.

Over the apex of the dental papilla there is apparently a very thin outline of dentine deposited, but within this, in the tissues of the apex of the dental papilla, there is also beginning an irregular formation of a hard matrix. Between the cells of the pulp, trabeculae of a bone-like material are appearing. As development proceeds this substance increases until the final result is, as seen in figure 20 , that the primary apex of the tooth has a bone-like structure, consisting of cells imbedded in lacunae within a dense matrix. This has been called by Tomes ('04) 'osteo-dentine.'

A similar difference between the labial and oral sides is noted in the cells on the margin of the dental papilla, which are be- 
coming odontoblasts. In the basal half of the papilla (fig. 14), odontoblasts occur only on the labial side opposite the tall ameloblasts, the peripheral cells of the other sides being still irregular or cuboidal in shape. Farther forwards the odontoblasts are found also on the lateral and mesial surfaces of the dental papilla, but not on the lingual. In the apical one-fourth of the dental papilla odontoblasts occur all round, measuring 20 to $24 \mu$ in length, and are engaged in the formation of dentine (fig. 13). The dentine is thickest on the labial side.

In the region where enamel and dentine formation has begun no mitoses were seen in the formative ameloblastic and odontoblastic cells, but posteriorly, where the deposition of enamel and dentine has not yet commenced, many mitoses occur in the layers of developing ameloblasts and odontoblasts, as well as elsewhere. The nearer one approaches the basal margin of the enamel-organ the more numerous are the mitoses and it is apparent that it is principally in this region that growth by addition of new cells is taking place.

\section{One day old}

At the end of the first day of post-natal life, there has been great progress in the enamel and dentine formation, and the narrow, pointed outline of the tooth has been already laid down. In the upper jaw the teeth measure about $2.3 \mathrm{~mm}$. in length and in the lower jaw about $3 \mathrm{~mm}$. Definite changes in its relation to the oral epithelium have occurred also at the anterior end of the tooth. The original epithelial stalk connecting the enamelorgan with the oral epithelium has increased in size and the end

Fig. 13 Cross-section of developing lower incisor of 21-day fetus of albino rat, nearer the anterior extremity of the tooth than figure 14 . Shows the greater thickness of the labial side of the enamel organ, as compared with that of the other sides, and shows odontoblasts around the entire periphery of the pulp. Enamel and dentine formation has begun. $\times 110$.

Fig. 14 Cross-section of developing lower incisor of 21-day fetus of albino rat, posterior to the region shown in figure 13. No enamel or dentine yet formed at this point. Odontoblasts highest on the labial aspect, decreasing in height laterally but not yet differentiated as columnar elements on the lingual side. Enamel-organ thickest on the labial side. $\times 110$. 

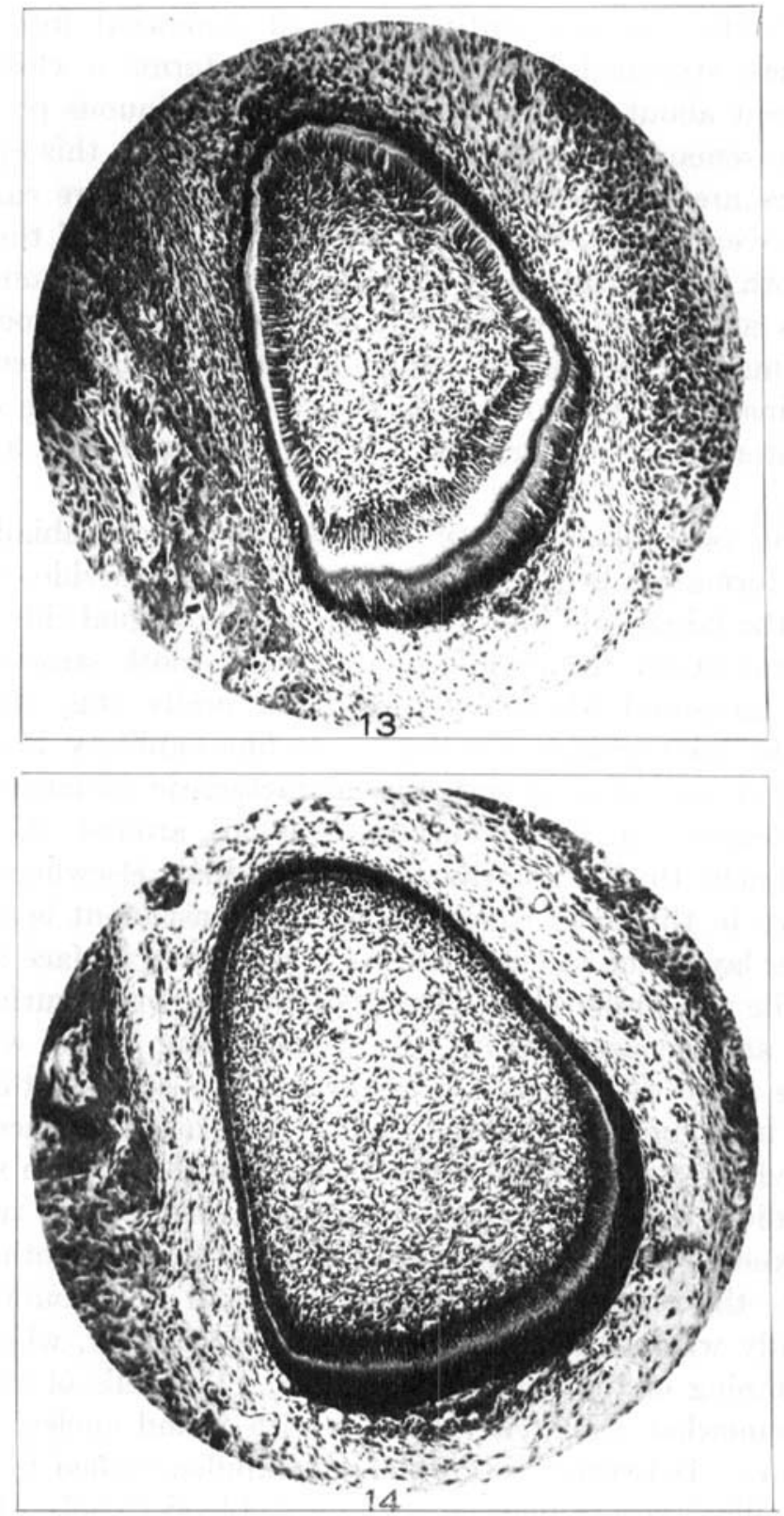
of the tooth has apparently advanced somewhat into it. So this thick stratified layer of epithelium forms a close-fitting investment about the tooth apex, and is continuous posteriorly with the remainder of the enamel-organ. But in this epithelial cap there are no ameloblasts and consequently there can be no enamel over the osteodentine which forms the tip of the primitive tooth. This substance forming the tip of the unerupted tooth is a form of secondary dentine with its cells located in the lacunae of the matrix. Passing backwards, one comes to the ordinary dentine containing the vascular pulp with odontoblasts situated at the periphery of the pulp-chamber in a regular manner.

As the odontoblasts were first differentiated labially, and dentine formation began there before on the other side, the dentine of the labial side is thicker than on the lingual side. Thus at a point about the middle of the entire tooth structure, the dentine measured $54 \mu$ labially and $20 \mu$ orally (fig. 15). Between the odontoblasts are numerous fine capillary loops. At this region may also be seen the characteristic structure of the enamel-organ (fig. 15). This extends all around the tooth, but is much thicker on the labial side than elsewhere. This difference in thickness is seen in all the constituent layers. In the inner layer, the tall ameloblasts of the labial surface measure $40 \mu$, while the similarly situated cells on the other surfaces are cubical and measure only $10 \mu$. Comparing these with the previous stage described, it is seen that the cells on the labial surface have increased and those on the other surfaces have decreased. Of the middle layer on the labial side, the stratum intermedium is a distinct line of cuboidal cells, one to two rowe in thickness, lying behind the ameloblasts. The other constituent - the original enamel pulp--is small in amount and is principally within the elevations of the outer layer, which form the beginning of the epithelial papillae. The cells of the outer layer, somewhat irregular in shape with round nuclei, are in a single row. Between the developing papillae (called by Sachse Stützpapillen) are numerous capillary blood-vessels. On the other surfaces, practically nothing remains of the middle layer, 
although the outer layer still persists as a layer of flattened cells. Thus lingually the enamel-organ is represented by only two rows of cells - one representing the inner, the other the outer layer of the enamel-organ.

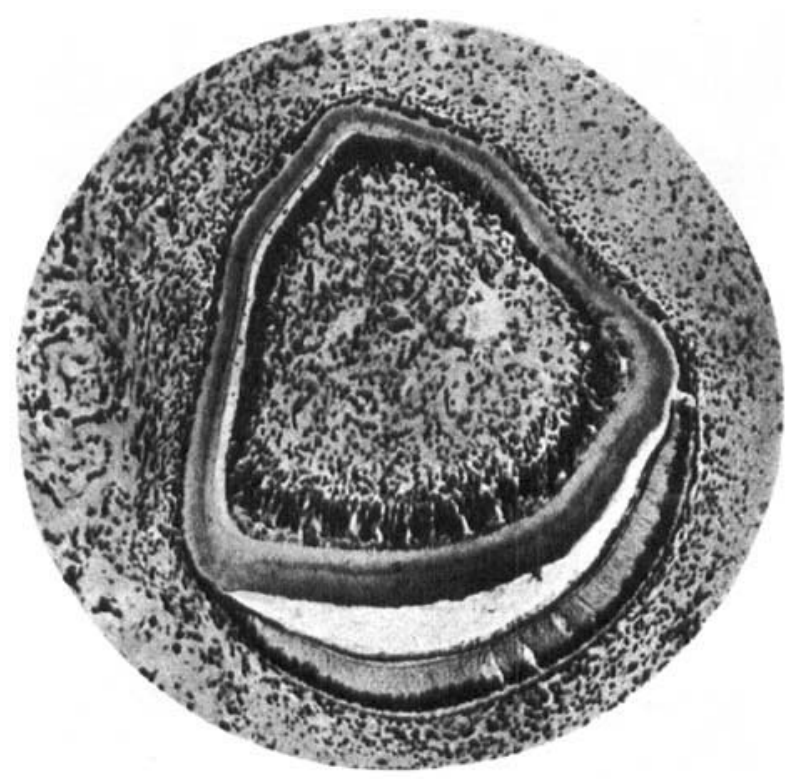

Fig. 15 Cross-section of developing lower incisor of 1-day albino rat, showing the great development of the ameloblasts on the labial side, and the thinness of the enamel-organ elsewhere. The space between the ameloblasts and the dentine is an artefect, and was formerly partly filled by the enamel, which has disappeared in the process of decalcification. In the layer of odontoblasts are seen the nuclei of the endothelial cells of the walls of capillaries. $\times 110$.

\section{Two days old}

Figure 16 shows a longitudinal section of a 2-day upper incisor. The epithelial enamel-organ is continuous over the whole tooth, but only shows its specialized functioning structure on the labial side. On the lingual side it is still intact and consists only of two rows of cuboidal or flattened epithelial cells. On the labial side, along the region where enamel has been formed (fig. 17) the 

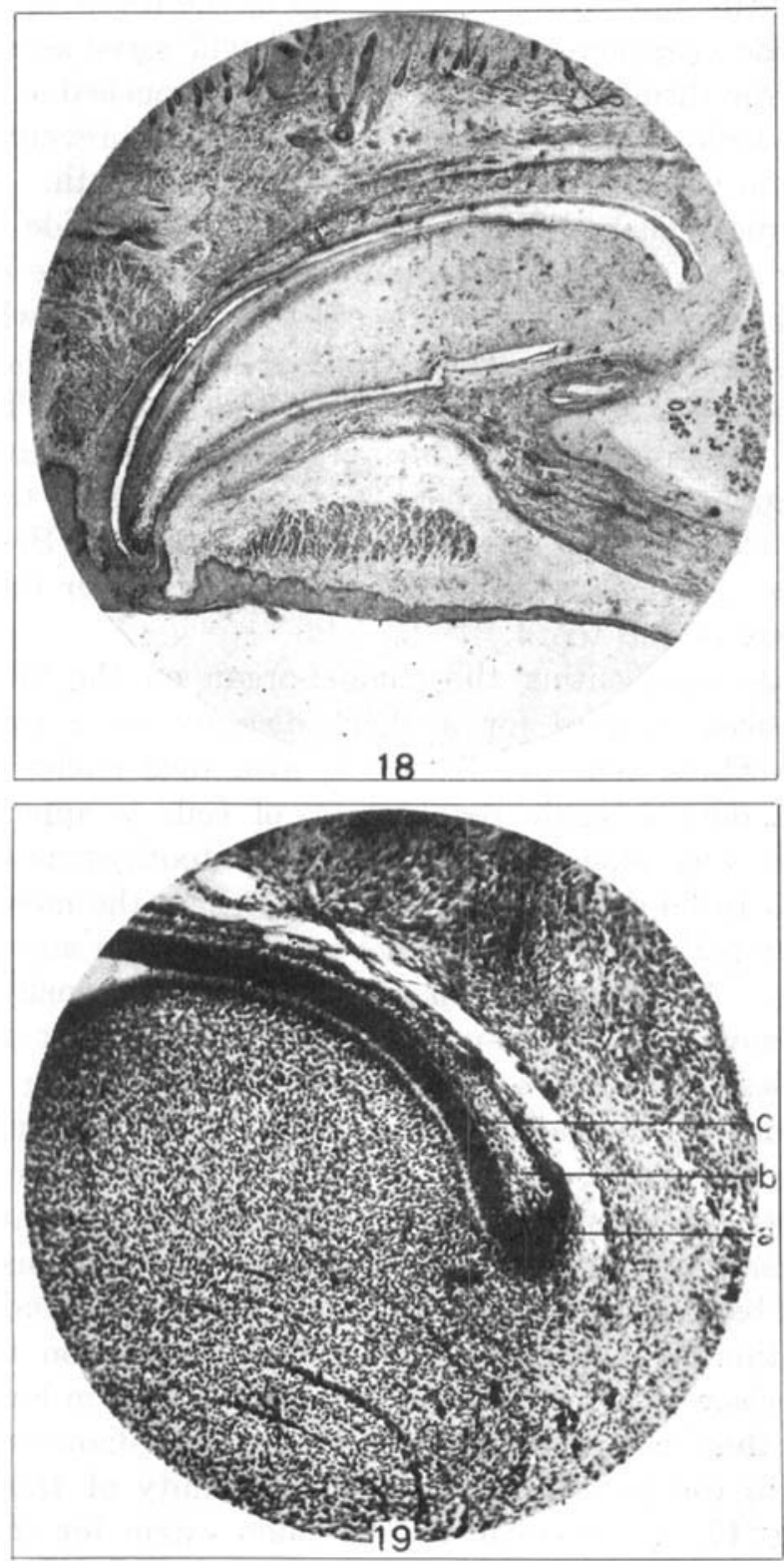

Fig. 16 Longitudinal section of upper incisor of 2-day albino rat showing the enamel-organ continuous over the labial surface and terminating posteriorly in the thickened margin. $\times 18$.

Fig. 17 Small portion of preceding figure more highly magnified, to show the structure of the enamel-organ and the odontoblasts. a, outermost layer of enamel-organ and epithelial papillae; b, enamel pulp; $c$, stratum intermedium; d, layer of ameloblasts; e, layer of dent:... f, layer of odontoblasts. $\times 175$. 
ameloblasts measure about $40 \mu$. These are backed by two rows of darkly staining flattened cells composing the stratum intermedium. Next to these is the looser arrangement of stellate cells, comparable to the enamel pulp of ordinary tooth development, but with much smaller spaces between the cells. This tissue is covered by the layer of cells constituting the outer layer of the enamel-organ, and the two together constitute the epithelial papillae. At the summit of each of these papillae the cells of the outer layer are grouped in a more compact manner. With higher magnification processes can be seen running from the ameloblasts into the developing enamel-the so-called enamel processes of Tomes.

At the basal formative part of the enamel-organ the three original layers show distinctly. At the thickened basal margin of the enamel-organ, around its entire circumference, is a mass of rapidly dividing cells. As seen in figure 16 this thickened margin is more noticeable on the labial side. Its peripheral zone as seen in longitudinal sections is deeply staining and its cells, more or less columnar in shape, are compacted together. The interior, of more lightly stained appearance, is composed of oval or elongated cells, irregularly parallel, but more loosely arranged than the cells of the periphery. This region constitutes the site of origin of the cells of the ever-forming enamelorgan. From this pass forward the outer and inner layers, and between them, in larger quantity than is found more anteriorly, the tissue of the middle layer. This for a short distance is all enamel pulp and shows no differentiated layer of stratum intermedium.

In this formative region on the labial side, the inner layer consists of columnar cells, the future ameloblasts, in which many mitoses are seen. While the outer layer consists of cells which are columnar near the margin, a short distance anterior to this $(150 \mu)$ they change shape, first to cubical, then to flattened cuboidal. Between the two layers are cells representing the enamel pulp. At this region there are no papillae, although numerous blood-vessels are seen alongside the outer layer of the enamel-organ. About $0.5 \mathrm{~mm}$. from the basal end this outer 
layer of the enamel-organ becomes sinuous, and low papillae are being formed.

On the lingual side, the structure of the basal end of the enamelorgan is similar, but somewhat simpler. Thus there are three layers at and near the basal margin, but soon, proceeding anteriorly, these become reduced to two by the disappearance of the middle layer. The lingual side then consists of two rows of cuboidal or flattened cells, one constituting the outer and the other the inner layer of the enamel-organ in this situation.

The dental papilla is made up of closely packed small stellate cells, with rounded nuclei. The mesenchymal cells which lie against the basal margin of the enamel-organ are rounded or irregular in shape, but within a short distance $(0.5 \mathrm{~mm}$.) anterior to this margin, the peripheral cells become first cubical and then columnar in shape. Where they are beginning to form dentine they measure $30 \mu$ in length. From the odontoblasts processes enter the dentinal tubules of the dentine. The outer surfaces of the odontoblasts from which these processes arise show a distinct cuticular margin. Between the odontoblasts at short intervals capillaries form loops around the cells. These are evidently for the purpose of insuring an ample blood supply to these functionally active cells.

\section{Four days old}

By 4 days of age there has been continued growth, and deposition of enamel and dentine. The upper incisor measures 3.6 $\mathrm{mm}$. in length and the lower $5 \mathrm{~mm}$. The position of the apex of the tooth is in close relation to the oral epithelium (fig. 18). A thickened mass of epithelium, partly a derivative of the original stalk of the enamel-organ, and partly an ingrowth from the

Fig. 18 Longitudinal section of upper incisor of 4-day albino rat, showing the increased curvature of the outline of the tooth and the relation of the apex of the tooth to the ingrowth of the oral epithelium. $\times 16$.

Fig. 19 Longitudinal section through basal end of labial side of enamelorgan of 4-day albino rat showing the region of the thickened margin. a, margin composed of mass of proliferating cells; $b$, region where three layers are seen; $c$, region where stratum intermedium becomes differentiated from rest of middle layer. Anterior to the region of this figure the epithelial papillae appear and the ameloblasts begin to form enamel. $\times 80$. 

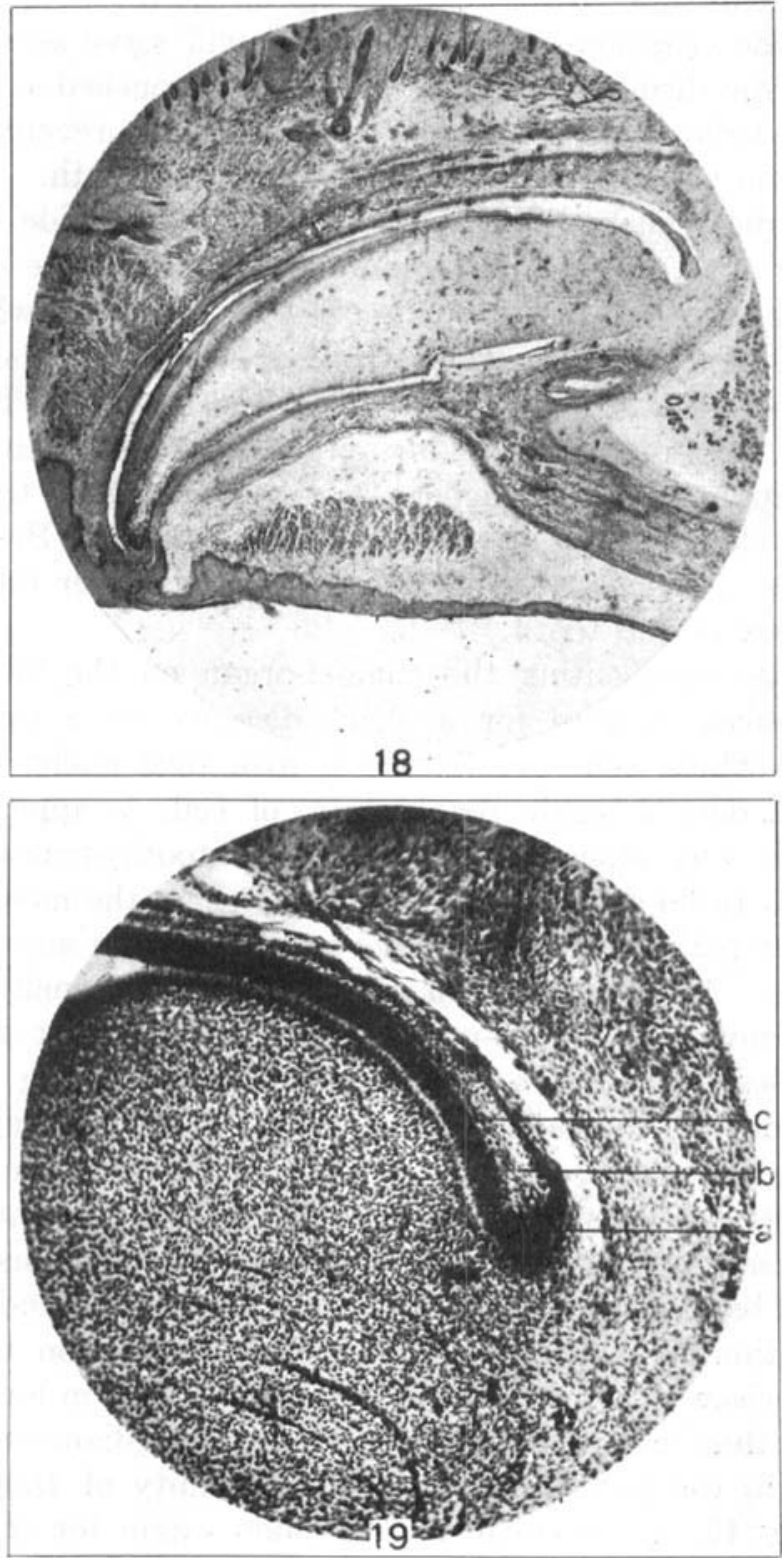
surface epithelium surrounding the tip of the tooth, is a preparation for the eruption of the tooth, and will serve as a resistant ring of tissue through which the tooth will be pushed at eruption. It may be looked upon as a protective device, to prevent adjacent tissues from being carried out by the erupting tooth.

The typical enamel-organ seen on the labial side does not cover the apex, for the tall columnar cells give place here, first to cubical and then to flat squamous epithelial cells, which form but a part of the thick mass of stratified epithelium, constituting the epithelial sheath over the end of the dentine. The other layers of the functioning enamel-organ also lose their identity at the region where the ameloblasts cease to have their characteristic elongated form. As maintained by von Brunn ('87) and Sachse ('94), there is no enamel apparent over the dentine at the apex of the tooth.

The cells representing the enamel-organ on the lingual side can be traced forward for a short distance as a two-layered stratum. These cells are flattened, with oval nuclei. Beyond this point only a single regular row of cells is apparent, and about half way along the length of the tooth-structure, even this ceases to be definite, and apparently here the mesenchymal cells of the peridental tissues have grown between and scattered these cells. As a result of this activity of the mesenchymal cells in this region, the enamel-organ now ceases to exist as a complete conical investment of the tooth. Approaching the apex of the tooth on the lingual side, one finds the prolongation of the epithelial sheath as a thin layer of flattened cells which thickens as it passes forwards into the epithelial sheath.

The basal formative end of the enamel-organ consists of a thickened band of tissue, as shown in figure 18, and under higher magnification in figure 19. This end is thicker on the labial side than elsewhere and it curves inwards, as seen in longitudinal sections, thus considerably diminishing the diameter of the entrance to the pulp-chamber. The extremity of this mass of tissue (fig. 19, a), constitutes a common origin for the several layers of the enamel-organ and contains many dividing cells. A short distance (0.1 to $0.2 \mathrm{~mm}$.) from the extremity (fig. 19, b) 
the cells form three layers, inner, middle and outer. The inner and outer layers, made up of columnar elements, stain more darkly than the middle layer, and the inner is thicker than the outer. The middle layer consists of elongated cells with oval nuclei, arranged for the most part with their long axes parallel to the surface of the enamel-organ. Frequent mitoses are also to be seen here, especially in the inner layer.

In the region about $0.6 \mathrm{~mm}$. anterior to this (fig. 19, c), where enamel formation has not yet begun, the innermost layer shows a single row of distinct tall columnar cells, the ameloblasts. The middle layer now shows two subdivisions (a) two or three layers of compacted flattened cells lying against the ameloblasts, and composing the stratum intermedium, and (b) a somewhat thicker stratum, lightly staining, of more loosely arranged cells, constituting the enamel pulp. The outermost layer is a single row of cubical cells, which form a straight continuous surface for the enamel-organ. Beyond this layer and in contact with it are numerous small blood-vessels. Passing still farther forwards, the outermost layer becomes more sinuous in outline, and blood-vessels occupy the depressions between the elevations. This arrangement shows the beginning formation of the typical epithelial papillae.

\section{Seven days old}

At 7 days the tip of the tooth is in the oral epithelium (fig. 20 ), and ready for eruption, being separated from the outside by only a thin layer of superficial cornified epithelium. The epithelial tissues immediately about the apex of the tooth show the appearance of pressure atrophy. The cell boundaries are more indistinct than elsewhere, the tissue takes the acid stain deeply, and there is increased granularity--evidently degenerative effects due to the pressure of the advancing tooth.

In the upper jaw, the basal end of the tooth in its backward growth has reached the region of the maxilla, into which it continues to grow, pushing before it a little pocket of thin bone. The average length of the upper teeth at this age is $5 \mathrm{~mm}$., and of the lower teeth, 7 to $8 \mathrm{~mm}$. Their pointed apices, and their comparatively slight curvature are shown in figure 24 . 


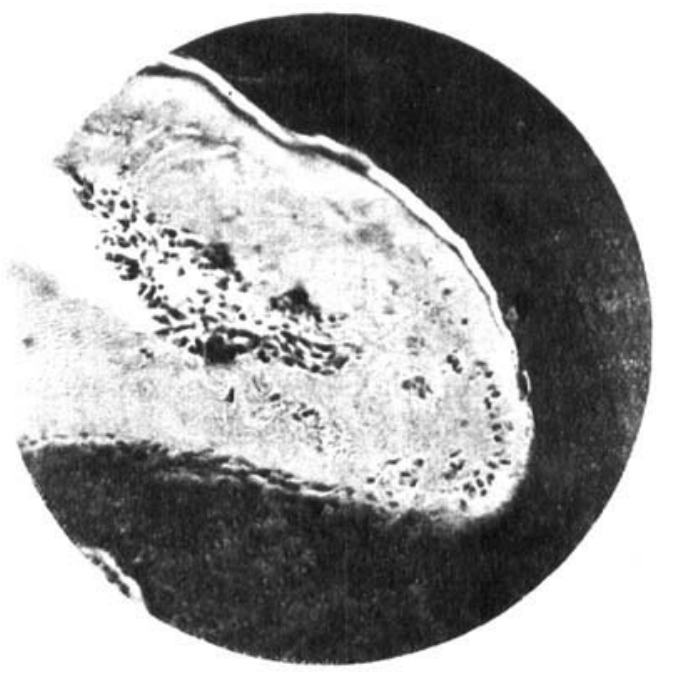

Fig. 20 Osteodentine of apex of tooth of 7-day albino rat imbedded in the surface epithelium, showing cells in the lacunae in the matrix. $\times 175$.

\section{ERUPTION OF TEETH}

Eight to ten days

During the process of eruption (fig. 21), the tooth and its formative organs gradually move forward as a whole, and the apex of the dentine forming the anterior end of the tooth pierces the surface epithelium. This procedure is accompanied by new changes in the tooth-forming organs. For while the same process of cell-division continues at the basal end of the dental papilla and enamel-organ, these structures are subjected to

Fig. 21 Longitudinal section of the upper tooth of an 8-day albino rat, showing the apex of the tooth piercing the surface epithelium. $\times 10$.

Fig. 22 Longitudinal section of the upper tooth of a 12-day albino rat, showing the increased size and curvature of the tooth, the basal end directed more towards the palatal surface and the progression of the apex of the tooth through the epithelium. $\times 10$.

Fig. 23 Longitudinal section of the upper incisor of a 26-day albino rat, showing the well-established occlusal surface, the approximation of the basal end towards the palatal surface, abundant blood-vessels in the pulp, and the position of the granular osteodentine filling in apex of the pulp chamber. $\times 10$. 

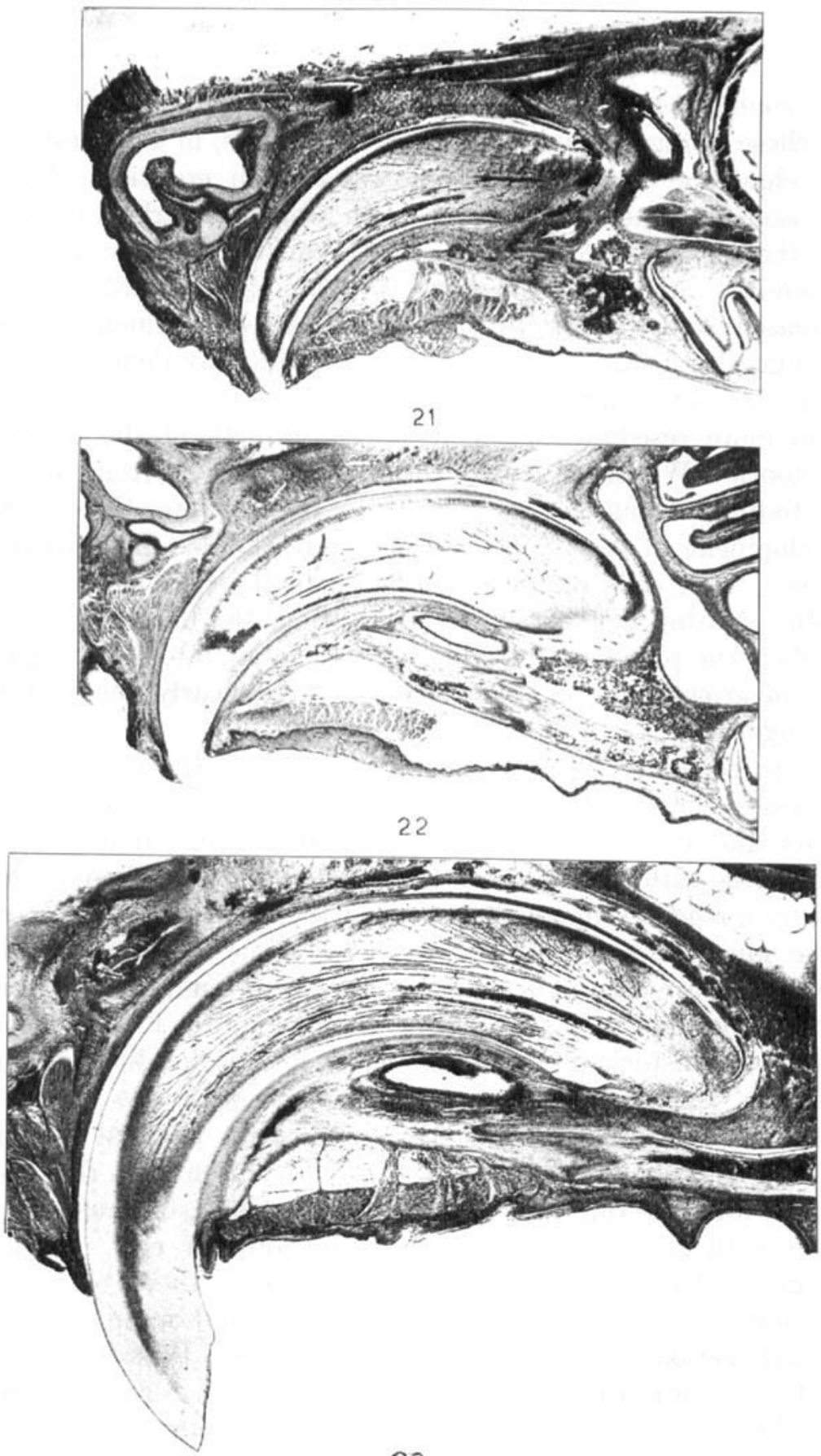
new conditions at the erupting end of the tooth. Before detailing these changes, it may be advisable to state, in a general way, the changing circumstances attendant upon eruption. Up to this time the anterior end of the tooth has been nearly stationary, but there has been continued growth backward of the posterior extremity. At this time the rate of progression forward is greatly increased, and the rate of progression backward much reduced. As suggested before, the process of eruption may depend largely upon the fact of increasing calcification in the bones, rendering them more resistant to the backward growth of the developing tooth. Whatever may be the causal factors, from now on the tooth continues to grow out at a regular rate, through the development of new cells at the basal end of the formative organs, these cells in turn giving rise to the hard parts of the tooth. Within a few days after eruption, the use of the tooth involves the process of attrition by which, in spite of the regular rate of growth, the exposed length is kept nearly constant for any age.

It is generally agreed that, by reason of the protoplasmic processes which extend into enamel and dentine from ameloblasts and odontoblasts respectively, these cells must be carried along with the tooth as it moves. Thus, as there is constantly a regeneration of these cells at the basal end of the tooth, there must be an opposite process of some nature by which these cells are eventually lost at the apical end, when carried thither by the outward progress of the tooth. First we may follow the history of the ameloblasts in this locality. Before eruption, the enamel-organ is continuous with the stratified epithelium forming the sheath around the gingival margin, and this relation continues at and after eruption. As the tooth moves forward during eruption the ameloblasts must move along with it and, when those at the anterior end approach the gingival margin, they must either be held there, or be carried out on the enamel until detached. On examining longitudinal sections at 12 days (fig. 22) it is seen that the ameloblasts, as they approach the gingival margin, become shorter and shorter, until, beneath the thickened sheath of epithelium 
forming the gingival margin they acquire a flattened form. As a continuation of these flattened cells next the tooth is seen, extending out into the space between the erupted tip of the tooth and the epithelial gingival margin, a thin layer of tissue, which must be looked upon as the portion of the enamelorgan which has been carried out during eruption. At later stages this same appearance occurs-a thin layer of flattened cells continuous with the enamel-organ lying in the space between the tooth and the epithelium of the gingival border. It may be that some of the cells are added to the epithelium of the gingival margin, but the majority appear to be continually carried out, and eventually detached.

The mesenchymal tissues of the pulp at the anterior end are little affected by the mere act of eruption and not until some days later when attrition begins, do we see definite changes. At eruption the anterior conical extremity of the tooth is formed of osteodentine, containing within its matrix the remains of scattered cells and blood-vessels. Immediately posterior to this begins the true fine-tubed dentine with a central pulp-chamber. The cells at the anterior end of the pulp-chamber are irregularly arranged, but following backwards one soon sees the odontoblasts in parallel arrangement at the periphery of the chamber. At 10 days, when the apex of the tooth has pierced the epithelium and is easily seen from the outside, the measurements of the upper and lower teeth are 7 and $11 \mathrm{~mm}$. respectively. At 12 days, they have increased to 7.5 and $11.8 \mathrm{~mm}$.

\section{CHANGES IN APEX OF TOOTH BY USE}

Already at 12 days, when one examines the exposed ends of the teeth, they show little pits, which have been caused by the pressure of the opposing teeth. At 14 days, the ends are flattened, and at 16 days, because of the increased obliquity of this flattened surface due to the wearing away of the lingual side of the dentine, they are acquiring a cutting edge. The length of these occlusal surfaces continues to increase so that by 19 or 21 days (fig. 24), they have nearly the appearance typically 
seen in the fully developed teeth. The osteodentine of the tip of the tooth is softer than is true dentine, for when the young tooth is dried this end shrivels and darkens in color. This cap of osteodentine on the end of the tooth may be useful, as suggested by Sachse ('94), because of its softness, in allowing the early formation of the functional occlusal surface. When this soft substance begins to wear away the tissues of the pulp would soon become exposed were there not a provision for the filling in of the apex of the pulp-chamber. This is effected by the formation of an irregular hard matrix, which may also be called osteodentine, within the extremity of the pulp-chamber. As

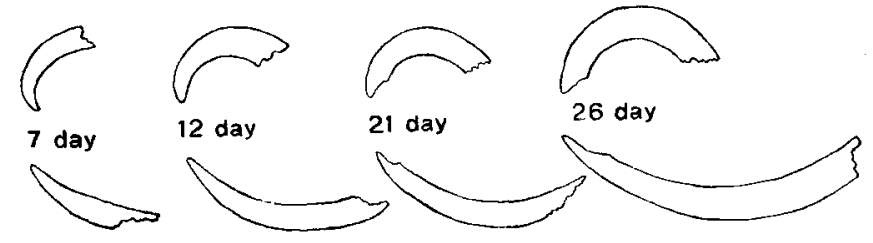

Fig. 24 Isolated upper and lower incisors of several ages of young albino rats. The pointed shape just before eruption is seen at 7 days. At 12 days, there is yet very slight change in the apices. At 21 days the occlusal surfaces are concave, and at 26 days they have nearly the typical mature appearance. $\times 2$.

the outer surface of the tooth wears away, this formation is constantly taking place a short distance from the occlusal surface.

Thus in examining a longitudinal section of the tooth at an age when the process of attrition has begun, and the typical occlusal surface has been formed (e.g., 26 days, fig. 23), we find this form of secondary dentine or osteodentine filling in the distal extremity of the pulp-chamber. As one approaches the anterior end of the pulp-chamber, the pulp becomes more and more restricted and the blood-vessels appear congested. Proceeding distally, the irregular matrix formation is seen between the cells and blood-vessels and finally near the occlusal worn surface is a granular mass of osteodentine with no circulating blood in it, but spaces are still seen containing the remains of the pulp elements. Here the living elements have disappeared, 
but by staining (e.g., with acid fuchsin), the remains of these may be made out in less calcified spots in the matrix. Evidently the odontoblasts and other tissues of the pulp which move with the dentine, become more and more compressed at the narrowing apex of the pulp-chamber, and finally there is this irregular deposit of secondary dentine between them, which serves to obliterate the pulp-chamber. As the tooth moves out, this process is constantly going on, just in advance of the occlusal surface, and keeps pace with the process of attrition.

It is interesting to note the rate at which the teeth are increased in length during their formative period and prior to attrition.

\begin{tabular}{|c|c|c|}
\hline & $\begin{array}{c}\text { Upper } \\
\mathrm{mm} .\end{array}$ & $\begin{array}{l}\text { Lower } \\
m m \text {. }\end{array}$ \\
\hline 1 day old... & 2.3 & 3 \\
\hline 4 days old. & 3.6 & 5 \\
\hline 7 days old. . & 5 & $7-8$ \\
\hline 10 days old. . & 7 & 11 \\
\hline
\end{tabular}

As will be seen later, this exceeds the rate at which the mature tooth continues to grow out.

DESCRIPTIOX OF MATURE TOOTH AND TOOTH-FORMING ORGANS, IN FIVE-MONTH ANIMAL

In the mature tooth, the general relations are shown in figure 25, made from a photograph of a decalcified section of the upper tooth of a 5-month animal. The regular curved outline is seen, with the greater proportion of the length imbedded within the jaw, and only a small part projecting. The formative end lies within an investment of bone belonging to the maxilla. At this end the dentine is very thin and the pulp greatest in amount. As one goes forward, the dentine increases regularly in thickness while the pulp-chamber becomes smaller and smaller. The vacuolated appearance at the anterior end of the chamber is due to shrinkage of the pulp tissue during fixation. The enamel has been lost in the process of decalcification except over the basal third. Numerous blood-vessels are seen within the pulp. 

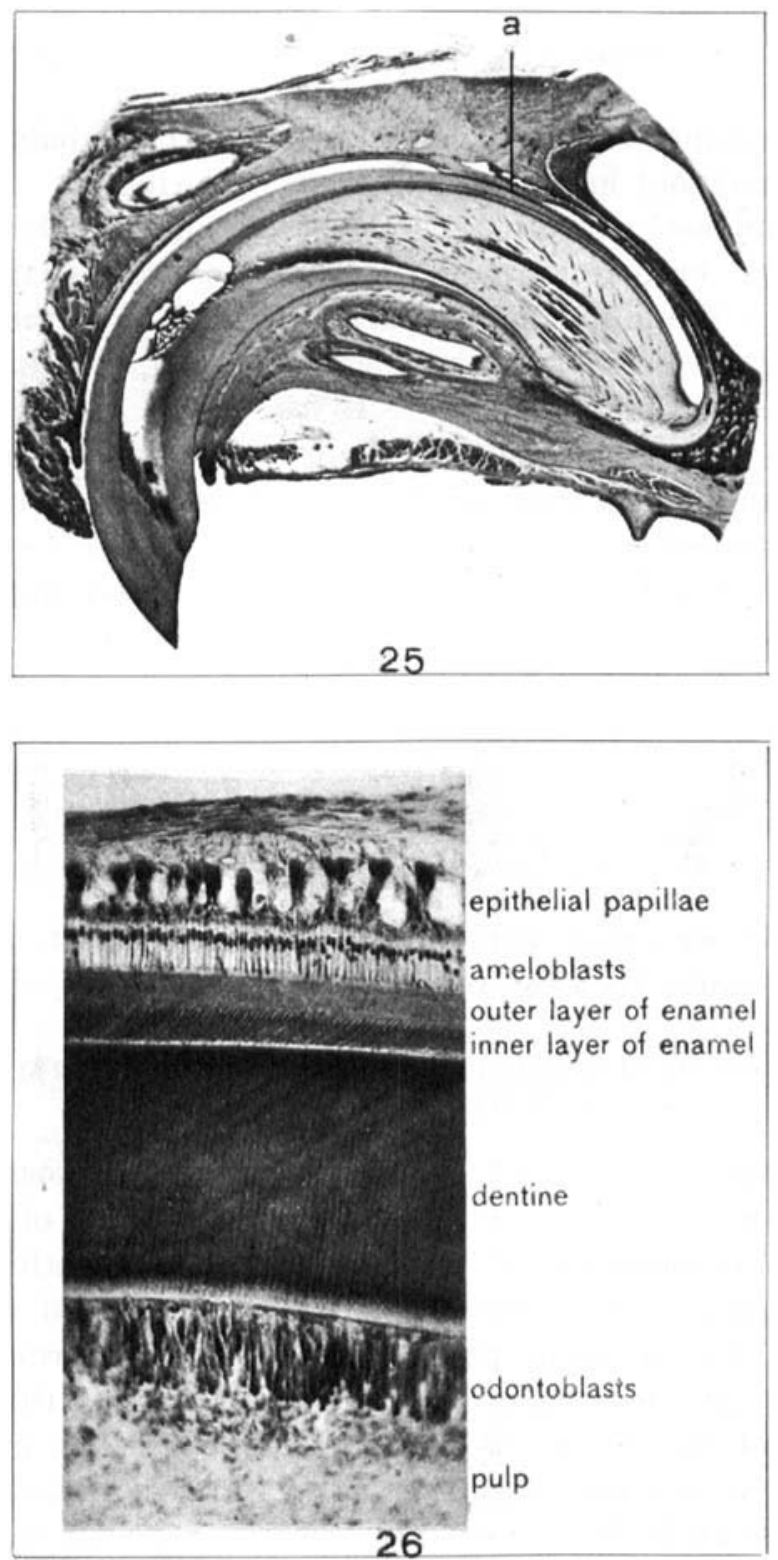

Fig. 25 Longitudinal section of upper incisor of a 5-month albino rat. The letter $a$ shows where the next illustration (fig. 26) is taken. $\times 6$.

Fig. 26 Small portion of the preceding, more highly magnified, to show the enamel-organ and the enamel, and the odontoblasts and dentine. $\times 135$. 
The enamel-organ is continuous over the convex labial surface of the imbedded portion of the tooth but is restricted to the most posterior region of the other surfaces, extending only $1 \mathrm{~mm}$. forward from the basal margin. The enamel-organ differs in its structure in three regions of the labial side, and may be described separately in these three parts: (1) at the basal formative end, (2) near the gingival margin and (3) in the long intervening region. In (1) the enamel-organ is being constantly regenerated by the addition and growth of new cells. In (2) the enamel-organ is undergoing a retrograde process, while (3) represents the region where the enamel-organ is at its highest functional development, although its activity in increasing the thickness of the enamel is restricted, as noted before, to the basal third or less in the upper and to the basal half in the lower tooth.

Considering first the region (3), as shown in figure 26 , the enamel-organ is conspicuous by reason of its tall ameloblasts and the high, narrow papillae. The enamel-organ is described in three layers-inner, middle and outer. The inner layer consists of the ameloblasts, which measure about $40 \mu$ in height, with nuclei situated towards the outer end of the cells. The middle is composed of two strata (a) stratum intermedium, and (b) enamel pulp. The stratum intermedium is formed of 1 or 2 rows of fairly regular cuboida cells resting upon the outer ends of the ameloblasts, but the enamel pulp is not now recognizable as a distinct layer and exists principally within the papillae. The outer layer of the enamel-organ consisted originally of a single layer of cells, but these are no longer regular in form or arrangement. Together with the remains of the enamel pulp, the outer layer forms the papillary elevations, 60 to $70 \mu$ in height. These papillae are surrounded by an abundant capillary blood supply for the nourishment of the cells engaged in the formation of the enamel, and the purpose of the elevations is apparently to increase the surface area through which absorption may take place from the blood-stream.

The enamel is in two layers (fig. 26), the rods while traversing the inner layer being very distinct, and inclining towards 
the apex of the tooth at an angle of from 50 to $54^{\circ}$ with the dentine surface. The continuations of these rods in the outer layer are not so distinctly seen, but the inclination, as made out in thin sections, is still greater towards the apex, forming an angle of from 20 to $25^{\circ}$ with the plane of the surface of the dentine. As noted before in the study of enamel, the rods in the inner layer, when observed in cross-sections of the tooth, decussate at an angle of from 70 to $90^{\circ}$, but when they reach the outer layer all run parallel. The fact that the rods run in these various directions seems incontrovertible, but in the light of our present knowledge of enamel formation it is difficult to understand how this condition is arrived at. If each ameloblast is responsible for an enamel-rod, then it follows that because the alternate layers of rods are oblique to one another, the ameloblasts responsible for these series of rods must have changed their relative positions during the process of formation of these rods. No such phenomenon has been observed, or even suggested. The other possibility is that the matrix of the rods is formed in a regular manner, but that afterwards, before calcification is complete, the rods become re-arranged owing to pressure strains.

The plane of direction of the rods is suggestive of the importance of the enamel-organ in the persistent growth. For always the general plane of the rods, as they leave the enameldentine junction, is towards the outer end of the tooth, as if the ameloblasts, while engaged in enamel-formation were always held back by the enamel, in which their processes were imbedded.

The basal formative end of the enamel-organ (region 1) in the adult animal corresponds very closely in structure with what has already been described for earlier ages, e.g., 4 days. This is the region where the enamel-organ is constantly being renewed, and it retains the same embryonal character at all stages of development.

At the anterior end where the enamel-organ is continuous with the surface epithelium (region 2), a gradual transition oc- 
curs between the typical enamel-organ and the stratifed squamous epithelium (fig. 27). As one follows the innermost layer of the enamel-organ forward, the cells become shorter, until they are cubical and finally flattened in shape. Here the other layers also lose their regular arrangement, and form, with the preceding, a thin layer of stratified cells. This layer can be followed directly into contact with the epithelium of the gingivus.

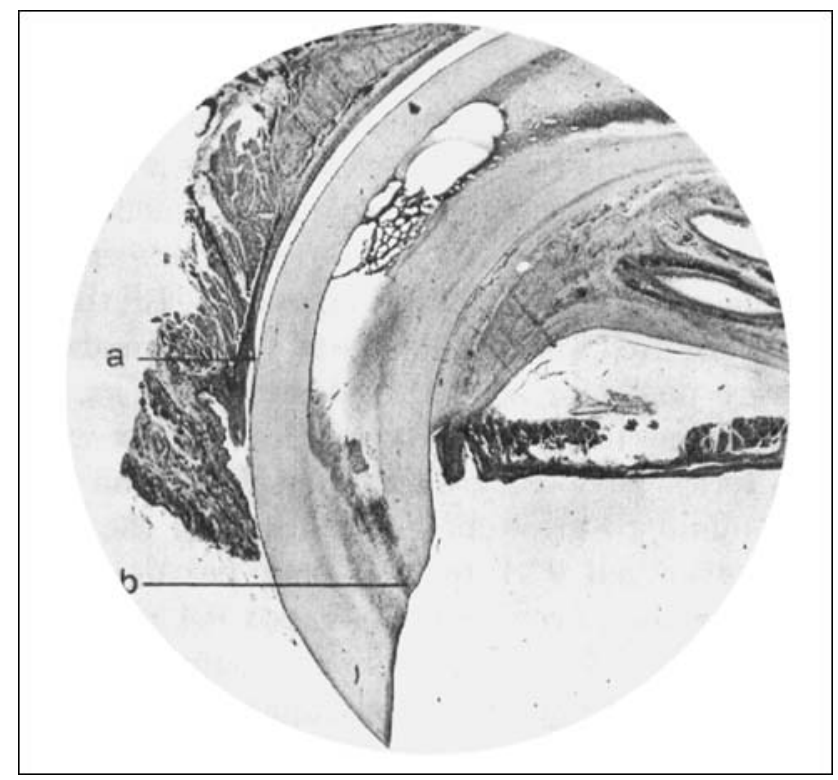

Fig. 27 Longitudinal section of the apex of the tooth of a 5 -month albino rat, showing at $a$ the position of the outward prolongation of the remains of the enamel-organ, and at $b$ the more granular osteodentine filling in the apex of the pulp chamber. $\times 10^{\circ}$.

The cells, however, do not lose their identity in the surface epithelium but remain separate as a thin layer lying against the enamel (fig. 27, a). This thin layer of epithelium, therefore, represents the ultimate fate of the enamel-organ after it has completed its functional activity. It is being continually pushed out and its most anterior part must be continually being lost. 
Two methods were used for determining the rate of growth of the incisor teeth (a) cutting off one or more teeth at the gingival margin and (b) making marks upon the enamel. The results here given are based on the latter method, as giving more nearly the normal rate of growth. By means of a dental engine, the animal always having been anesthetized, a fine transverse notch was made on the enamel of the incisors a short distance from the gingival margin. The interval between this mark and the tip of the tooth was then measured. At the end of about a week the distance between these two limits was again taken, and the difference between the two measurements showed the amount of wearing away. Two series of experiments were made by this method upon adult animals. In the first series six animals were used and in the second four animals, and measurements were made for several consecutive weeks. The longest period that one individual was studied was six weeks.

The two series gave very similar results. The lower tooth was always found to grow more rapidly than the upper. The upper tooth averaged 0.31 to $0.32 \mathrm{~mm}$. per day, or $2.2 \mathrm{~mm}$. per week, while the lower tooth averaged $0.4 \mathrm{~mm}$. per day, or $2.8 \mathrm{~mm}$. per week. No doubt there are many variations of the rate of growth under different circumstances, so that these figures must be taken as representing the average rate under one particular set of conditions. The food of these animals was the mixed diet now in use in the rat colony of The Wistar Institute. A short series of trials was made with animals kept in a large glass jar and given only soft food. In these animals the rate of wearing away corresponded very closely to that seen in animals which have also hard food and have the opportunity of gnawing. In these, therefore, the interaction of the opposing teeth must have caused the attrition.

For assistance with these experiments we wish to thank Dr. Stotsenburg, who greatly aided us in carrying out our observations. 
It is interesting to compare these results with those obtained on the rabbit-the only other rodent which has been carefully studied in respect to the growth of its incisors. MacGillavry ('75), using a young adult rabbit, made marks upon its lower incisors $2.5 \mathrm{~mm}$. and $3 \mathrm{~mm}$. from the tip. After five to seven days the marks had disappeared. Evidently the rate of growth was about 2.5 to $3 \mathrm{~mm}$. per week. Noë ('02) used a rabbit which happened to possess overgrown teeth. The animal accidentally broke off the lower incisors in the bars of its cage, and Noë made observations upon the rate of their growing out. This he found to be $.615 \mathrm{~mm}$. per day, or $4.3 \mathrm{~mm}$. per week. This is larger than MacGillavry's results and may have been due to the unopposed growth and to the other abnormal conditions which may have been present in the formative organs.

Using MacGillavry's figures for comparison, it would seem that the lower teeth of the albino rat and of the rabbit grow out at about the same rate.

\section{OVERGROWTH OF INCISORS}

Examples of overgrowth of the incisors of rodents, especially in rabbits and hares, which were hunted as food, must have been observed from early times. In the older literature, they are referred to principally as curiosities, which have excited the interest of whoever has found them. Iater the causes of the malformations were also considered. Thus Jenyns ('29), to cite only one observer, found several examples in wild rabbits, and has given a good illustration of the curved aspect of the teeth. He also clearly states the several causes which, in his opinion, may give rise to the condition. In addition to the one usually accepted at his time-accidental breaking off of one tooth-he considered also as causes (a) too soft food, (b) morbid or too rapid secretion of the osseous matter of the teeth, and (c) dislocation of one of the condyles.

Wiedersheim ('02-'03) has reported a case occurring in a rat, where he found an associated assymmetry of the cranium. He is in doubt as to which was cause and which was effect-the overgrowth of the teeth or the assymmetry of the cranium. 

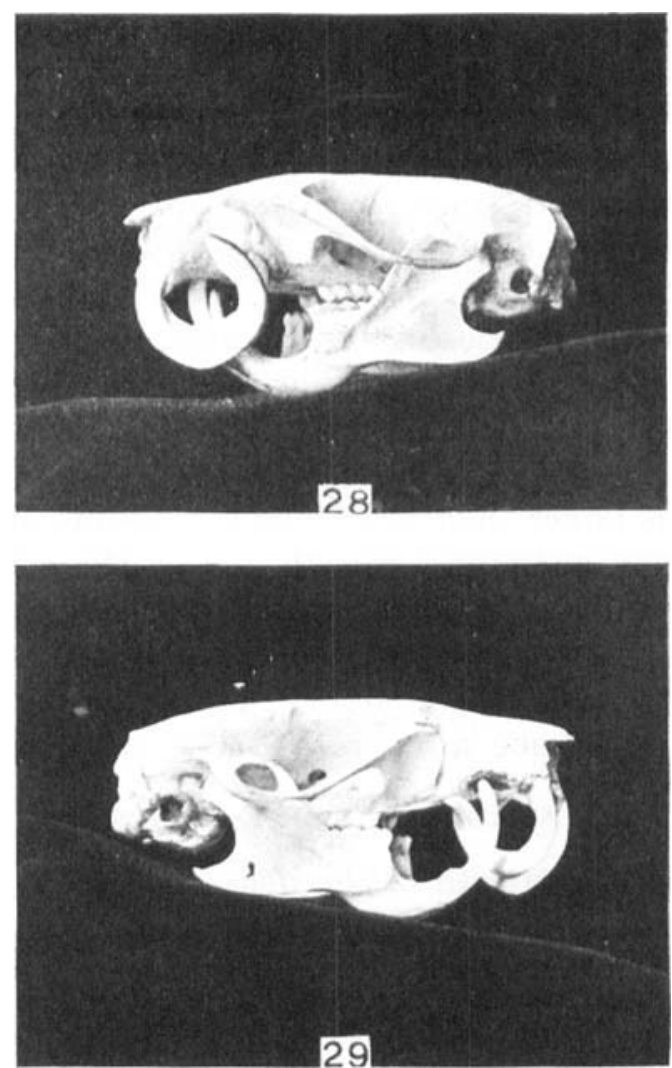

Fig. 28 Cranium of albino rat, showing the overgrown upper incisors recurving to the left side. The left incisor passes to the outer sicle of the skull, while the apex of the right incisor has penetrated the bone of the maxilla in the region of the basal end of the left incisor. $\times 1$.

Fig. 29 Cranium of the same albino rat shown in the preceding figure, viewed from the right side. It shows the overgrown lower incisors recurving to the right side, and the cavity which the right incisor has worn in the palate bone.

Figures 28 and 29 show a skull obtained some years ago from the rat colony of The Wistar Institute by Dr. Stotsenburg, and prepared in the Histological Laboratory by Miss E. F. Brooks. The upper teeth curved to the left side of the head and the lower to the right side. As seen in figure 29, the right lower has penetrated through the bone of the palate into the 
nasal chamber, while the right upper (fig. 28) has recurved and grown into the maxilla.

In The Wistar Institute rat colony, at the time when the animals were fed on bread and milk, frequent examples of this and similar conditions were found, but now under a more varied mixed diet they practically never occur.

Beretta ('13) has recently made an analysis of these abnormalities and has classified them in three groups.

(1) Overgrowth of the upper and lower incisors through lack of an opposing tooth.

(2) Overgrowth of the incisors of the upper and lower jaws through deviation of the jaws.

(3) Prognathism of the lower jaw, and as a result, overgrowth of the incisor of the lower jaw.

In the present instance, diet seemed to be the controlling factor, probably by reason of its influence on the hardness of the bone of the alveoli from which the teeth grew out.

\section{SUMMARY}

The rate of growth of the upper and lower incisor teeth of Mus norvegicus albinus, in the mature animal, averages 2.2 and $2.8 \mathrm{~mm}$. per week, or $12.5 \mathrm{~cm}$. and $14.5 \mathrm{~cm}$. per year, respectively.

Growth is due primarily to the proliferation and growth of cells at the basal end of the enamel-organ, where new enamelforming cells arise, and at the basal end of the dental papilla where new dentine-forming cells develop.

The enamel-organ of the adult forms a narrow circular band around the basal end of the tooth, and extends forward from this on the labial side only. It coincides in its lateral boundaries with the enamel, and extends along the entire imbedded portion of the tooth. Anteriorly, it comes in contact with the epithelium of the gingival margin, and is carried out continually as a narrow band of cells lying on the enamel, between the latter and the gingival epithelial tissue.

The first indication of the anlage of the incisors appears in 14-day-old fetuses. In fetuses, 21 days of age (just before 
birth), enamel and dentine formation is beginning. In animals 1 day old the upper and lower teeth measure 2.3 and $3 \mathrm{~mm}$. At 8 to 10 days the teeth erupt, and at 10 days measure 7 and 11 $\mathrm{mm}$. respectively. This period is therefore characterized by the rapid elongation of the teeth.

The process of attrition begins within a few days after eruption, so that by 19 or 21 days of age, the typical occlusal surface is formed. Up to the time of eruption the anterior end or apex of the tooth is immediately under the oral epithelium, while the basal or growing end is continually progressing posteriorly. After eruption, the basal end becomes nearly stationary in position, while the whole tooth structure is continually moving forward. The extra-gingival length of the tooth is kept constant, however, by the attrition of the occlusal surface, either through use in gnawing or by the action of the opposing teeth.

The histogenesis of the enamel-organ is practically completed by the 4th day after birth, although it does not attain its final relations to the tooth as a whole, until after eruption. In the 18-day fetus the enamel-organ is similar in all parts, and the cells of the inner layer measure the same, both lingually and labially. From this period forwards, however, the labial portion continues to progress towards its fully differentiated functional structure, while the lingual portion retrogresses, until at 4 days after birth the latter is disrupted, by the ingrowth of the surrounding connective tissue. Contrasting the cells of the inner layer--the potential ameloblasts-on the labial and lingual sides, they are practically the same in the 18-day fetus, but at 19 days they are found to measure 24 and $20 \mu$ respectively. In the 21-day fetus, they measure 30 to 34 and $12 \mu$, and 1 day after birth the true ameloblasts on the labial side have increased to $40 \mu$, while the non-functional cells of the lingual side are only $10 \mu$ in height. At 4 days, the latter cease to form a continuous layer, by reason of the dispersion of the cells by the surrounding connective tissue, except at the basal formative region.

Characteristic of the permanently-growing enamel-organ are the epithelial papillae, formed by the elevations of the outer 
layer of the enamel-organ, and the cells of the enamel pulp. Between these elevations are numerous capillaries which insure a rich blood supply to the enamel-forming cells.

There are three layers in the functional enamel-organ-inner, middle and outer. The inner is constituted of the tall ameloblasts, and the middle is made up of two divisions, (a) stratum intermedium and (b) enamel pulp. The latter unites with the single layer of cuboidal cells which compose the outer layer, to form the epithelial papillae (fig. 26).

The apex of the primitive tooth is formed of a variety of secondary dentine-'osteo-dentine' of Tomes-which is softer than true dentine, and differs in its structural arrangement (fig. 20). After eruption, this terminal portion of osteodentine is soon worn away by attrition, and the typical occlusal surface is developed, as seen at 19 or 21 days. At 21 and 23 days the first two molars erupt in both upper and lower jaws, and from now on the animal is able to secure food for itself, and if necessary can maintain an independent existence.

As the tooth continues to be worn away there is a provision for the continual filling in of the apex of the pulp-chamber by the formation of what may also be called osteodentine. This is a form of secondary dentine, containing, when first formed, cells and blood-vessels. This is always at a little distance, about $1 \mathrm{~mm}$., from the occlusal surface, but as any part of the tooth, in its outward progression, approaches the occlusal surface, the soft elements disappear within the osteodentine, and the latter forms a hard continuous surface with the adjoining true dentine. The position of this osteodentine is marked as a line on the occlusal surface of the teeth (fig. 5).

Prior to eruption there develops around the apex of the tooth, as it lies in contact with the surface epithelium, a thickened ring of stratified epithelium. This ring of tissue is pierced by the apex of the tooth at eruption, and would seem to have the function of serving as a resistant margin for the soft tissues, and of preventing other tissues being carried along with the erupting tooth. 
The length of the teeth varies with the size of the cranium (table 1) so that the persistent growth is not only sufficient to offset the continual attrition, but also serves to keep the length of the teeth in a definite relation to the length of the skull, as the latter increases in size.

The lower tooth is always longer than the upper, and this difference manifests itself even in the anlagen of these structures in the 19-day fetus (figs. 11 and 12).

The contour of the enamel, as seen in cross-sections, is characteristically different in the upper and lower teeth (fig. 4).

The enamel of the tooth is composed of two layers which are different in appearance. The enamel rods run in two sets which decussate with each other in the inner or plexiform layer, but they change their direction as they continue into the outer layer, so that in it they are all parallel. In longitudinal sections, the general direction of the rods (fig. 26), is to incline towards the apex of the tooth, as they run from the enamel-dentine boundary to the outer surface of the enamel.

In conclusion, we wish to thank Professor Piersol for generous assistance in many ways, and Professor Donaldson for his constant interest in the study. We also wish to acknowledge the kind assistance of Mr. E. F. Faber in the preparation of the drawings. 


\section{LITERATURE CITED}

AdLoff, P. 1898 Zur Entwicklungsgeschichte des Nagetiergebisses. Jena. Zeitschr. für Naturwissenschaft, Bd. 32, ss. 347-410.

BERETTA, A. 1913 La normala dentatura dei roditori in rapporto alle anomalie dentali in questi osservate. La Stomatologia, t. 10. Abstract in Deutsche Monatsschrift für Zahnheilkunde, April, s. 287.

von Brunn, A. 1887 Ueber die Ausdehnung des Sehmelzorganes und seine Bedeutung für die Zahnbildung. Arch. f. mikr. Anat., Bd. 29, ss. $367-383$.

BURCKHARDT, R. 1906 In Hertwig's Handbuch der Entwickelungslehre der Wirbeltiere, Bd. 2, Teil 1, Kapitel 4, ss. 349-456. "Die Entwickelungsgeschichte der Verknöckerungen des Integuments und der Mundhöhle der Wirbeltiere."

Cope, E. D. 1888 The mechanical causes of the origin of the dentition of the Rodentia. Amer. Nat, vol. 22, pp. 3-11.

Donaldson, H. H. 1912 The history and zoological position of the albino rat. Proceed. Acad. Nat. Sci., Philadelphia.

FreUnd, P. 1892 Beiträge zur Entwicklungsgeschichte der Zahnanlagen bei Nagethieren. Arch. f. mikr. Anat., Bd. 39, ss. 525-556.

Fritsch, C. 1914 Untersuchungen über den Bau und die Innervierung des Dentins. Arch. für mikr. Anat., Bd. 84, ss. 307-20.

HataI, S. 1907 On the zoological position of the albino rat. Biol. Bull., vol. 12 , pp. $266-273$.

JENYNS, L. 1829 Observations on a preternatural growth of the incisor teeth occasionally observed in certain of the Mammalia Rodentia. Loudon's Magazine Nat. Hist., London, vol. 2, pp. 134-137.

Jolyet et Chakrir 1875 De l'acte de ronger, étudié chez les rats. Comptes Rendus et Mémoires de la Soc. de Biol., pp. 73-74.

Löwe, L. 1881 Beiträge zur Kenntniss des Zahnes und seiner Befestigungsweise im Kiefer. Arch. f. mikr. Anat., Bd. 19, ss. 703-719.

MacGillavry, T. H. 1875 Les dents incisives du Mus decumanus. Arch. Néerl. Sc. exact. et nat., Haarlem.

Meyerheim, M. 1898 Beiträge zur Kenntnis der Entwicklung der Schneidezähne bei Mus decumanus. Dissertation. Leipzig.

Mummery, J. H. 1912 On the distribution of the nerves of the dental pulp. Philos. Trans. Roy. Soc., London, vol. 202, B., pp. 337-349.

Nö̈, J. 1902 Vitesse de croissance des incisives chez les Léporides. Comptes Rendus, hebd. des Séances et Mémoires de la Soc. de Biol., pp. 531-532.

OUdeT, J. E. 1823 Expériences sur l'accroissement continué et la reproduction des dents chez les lapins. Jour. de Physiol. Expér. et Patholog., Tomes 3 et 4 .

Owen, R. 1840-45 Odontography. London. 
Reichert, E. T., AND Brown, A. P. 1910 The erystallography of hemoglobin. Pub. Carnegie Inst. of Washington.

Retzivs, A. 1838 Bemerkungen über den inneren Bau der Zähne mit besonderer Rücksicht auf den in Zahn vorkommenden Röhrenbau. Müller's Archiv.

Roetter, F. 1889 Ueber Entwicklung und Wachstum der Schneidezähne bei Mus musculus. Morphol. Jahrb., Bd. 15, ss. 457-477.

RYDER, J. A.. 1877 The significance of the diameters of the incisors in Rodentia. Proc. Acad. Nat. Sci., Philadelphia, vol. 29, pp. 314-318.

1878 On the mechanical genesis of tooth-forms. Proc. Acad. Nat. Sci., Philadelphia, vol. 30, pp. 45-80.

SAchse, B. 1894 Entwicklung der Schneidezähne bei Mus musculus. Dissertation. Leipzig.

Stach, J. 1910 Die Ontogenie der Schneidezähne bei Lepus cuniculus. Extrait. Bul. d'Acad. Sc., Cracovie.

Tomes, C. S. 1914 A manual of dental anatomy; human and comparative. 7th Fd. Edited by H. W. Marett-Tims and A. Hopewell-Smith.

Tomes, J. 1850 Structure of the dental tissues of the order Rodentia. Phil. Trans. Royal Society of London, pp. 529-567.

Tullberg, T. 1898-99 Ueber das System der Nagethiere. Nova Acta Reg. Soc. Sc. Upsaliensis, Series 3, ss. 1-514.

WEBer, M. 1904 Die Säugetiere.

WiEdERsheim, R. 1902-03 Ein abnormes Rattengebiss. Anat. Anz., Bd. 22, s8. $569-573$.

Wilinams, J. L. 1896 The formation and structure of dental enamel. Dental Cosmos, vol. 38.

Woodward, M. J. 1894 On the milk dentition of the Rodentia with a description of a vestigial milk incisor in the mouse (Mus musculus). Anat. Anz., Bd. 9, ss. 619-631. 